\title{
The Effect of Surgical Guides on Heat Generation During Guided Implant Surgery: An in Vitro Study
}

\author{
Safa Tahmasebi \\ West Virginia University
}

Follow this and additional works at: https://researchrepository.wvu.edu/etd

\section{Recommended Citation}

Tahmasebi, Safa, "The Effect of Surgical Guides on Heat Generation During Guided Implant Surgery: An in Vitro Study" (2013). Graduate Theses, Dissertations, and Problem Reports. 3619.

https://researchrepository.wvu.edu/etd/3619

This Thesis is protected by copyright and/or related rights. It has been brought to you by the The Research Repository @ WVU with permission from the rights-holder(s). You are free to use this Thesis in any way that is permitted by the copyright and related rights legislation that applies to your use. For other uses you must obtain permission from the rights-holder(s) directly, unless additional rights are indicated by a Creative Commons license in the record and/ or on the work itself. This Thesis has been accepted for inclusion in WVU Graduate Theses, Dissertations, and Problem Reports collection by an authorized administrator of The Research Repository @ WVU. For more information, please contact researchrepository@mail.wvu.edu. 
The Effect of Surgical Guides on Heat Generation During Guided Implant Surgery: An in Vitro Study

Safa Tahmasebi, D.D.S

Thesis submitted to the

College of Human Resources and Education at West Virginia University in partial fulfillment of the requirements for the degree of

Masters of Science

in

Prosthodontics

Mark Richards D.D.S., M.S., F.A.C.P., Chair Hal Reed D.D.S., M.S. Michael Bagby D.D.S., M.S., P.H.D. Mohsen Ghalichebaf D.D.S., M.S.

West Virginia University School of Dentistry Department of Graduate Prosthodontics

Morgantown, West Virginia

2013

Key words:

Osseointegration, Computerized tomography, Surgical guide, Guided implant surgery, Dental implant 


\section{Abstract \\ The Effect of Surgical Guides on Heat Generation During Guided Implant Surgery: An in Vitro Study}

\section{Safa Tahmasebi, D.D.S., Amanda G. Hughart, B.S.D.H.}

Purpose: The purpose of this in vitro study was to evaluate the heat generated in bone by one implant drill system with and without using surgical drill guides. Temperature elevation during guided surgery was compared to that of conventional drilling in bovine femur specimens. Significant differences in temperature elevation between conventional osteotomy and guided surgical osteotomy were examined.

Materials and Methods: Conventional and Surgically guided osteotomies were performed in 117 randomized measurements with $\mathrm{K}$ type thermocouples in an in-vitro study using bovine cortical bone. Using an internally and externally irrigated implant system, intermittent drilling at 2second intervals at a constant speed of 2,000 rpm was performed with the aid of a drill press. Drills were replaced after every 20 uses. Maximum temperatures at $T_{1}(5 \mathrm{~mm})$ and $T_{2}(10 \mathrm{~mm})$ were recorded with computer software with and without a surgical guide within $1 \mathrm{~mm}$ distance from the osteotomy site. Thermocouple distances were measured after each preparation using a digital caliper. Total drilling time was recorded for both experimental conditions. Using recordings from the computer software, time interval above $47^{\circ} \mathrm{C}$ was measured for both guide and no guide and at both thermocouple depths.

Results: Higher maximum temperatures at both $5 \mathrm{~mm}$ and $10 \mathrm{~mm}$ were found with the use of surgical guides. Longer time interval of temperature elevations above $47^{\circ} \mathrm{C}$ was found when using a surgical guide. Finally, the drill time for both guide and no guide was found to be the same. Additionally, thermocouple distances were kept at a constant distance from the osteotomy site.

Conclusion: We conclude that the use of surgical guides generated more heat than conventional implant drilling. Significant differences were found at maximum temperatures and threshold levels with and without the use of surgical guides. Further studies need to be conducted to establish methods of controlling elevated temperatures when guides are used in surgery. 


\section{Acknowledgements}

West Virginia University Hospitals Radiology Department (Dee Headley)

West Virginia University, School of Dentistry, Department of

Prosthodontics

Gerald Hobbs, Ph.D. Statistician

Young and Stout Slaughter House, Clarksburg, WV

Amanda G. Hughart, B.S.D.H.

Matthew Bobbera, D.D.S. 


\section{Table of Contents}

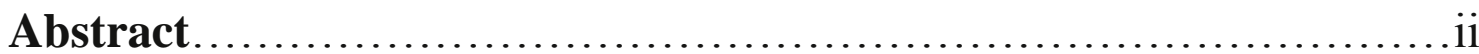

Acknowledgements.....................................................ii

Chapter I: Introduction

Background .......................................................

Statement of the Problem................................................ 3

Significance of the Study.............................................. 4

(Null) Hypothesis...................................................5

Definition of Terms.................................................. 5

Assumption.......................................................... 7

Limitations .......................................................... 7

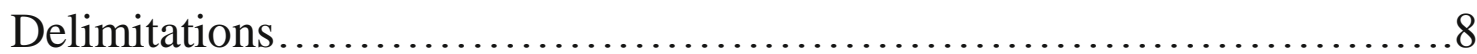

Chapter II: Literature Review

Background.....................................................99

Force

Speed

Time

Specimen

Irrigation

Instruments of Heat Assessment

Modes of Drilling

Drill Wear

Drill Guides

Chapter III: Materials and Methods

Chapter IV: Results

Chapter V: Discussion

Chapter VI: Conclusion

Chapter VII: Appendix A

List of Figures

Chapter VIII: References 


\section{Chapter I}

\section{Introduction}

\section{Background}

Dental implants have become a routine dental treatment when it comes to replacing single or missing teeth. Today we expect dental implant success rates in the high ninety percent range, however failures are still encountered. The most common surgical failures revolve around parameters set forth by the process of osseointegration. The concept of osseointegration is based on a series of research that began in 1952 when Per-Ingvar Brånemark was conducting microscopic studies on bone marrow in rabbit's fibula. ${ }^{14}$ (Brånemark) Studies were conducted by attaching optical systems made out of implanted titanium chambers for transillumination of a thin layer newly formed tissue. In early 1960 it was discovered that these optical chambers could not be removed from the bone once they were healed. This led to further experimental work that was conducted aiming at development of clinical procedures for rehabilitation of edentulism using fixed bridge reconstruction. Brånemark defined osseointegration as a direct structural and functional connection between ordered, living bone and the surface of a load carrying implant. $^{14}$

Bone tissue is one of the most cellular and vascularized tissue in the body. In Implant dentistry, progression of bone healing dictates the outcome of an implant. ${ }^{49}$ (Weiss CM 1986). "The extent of damage relates directly to the amount of heat that is applied to the bone, e.g., by insufficient cooling or dull drills. The frictional heat generated by such procedures generally gives to a zone of devitalized bone around the 
burr holes. The extent of necrotic bone varies exponentially with the magnitude of the temperature". ${ }^{48}$ Brånemark stated that the frictional heat generated at surgery will cause necrosis of surrounding cells and represents a primary cause for bone necrosis. It is important to use profuse irrigation, light pressure and sharp drills to ensure that the bone does not go above $47 \mathrm{C}$ for 1 minute. ${ }^{26}$

Multiple in vitro and in vivo studies have been performed in efforts to assess the parameters that directly or indirectly affect the process of osseointegration. One area of research pertained to the amount of heat generated during the process of implant bed therapy. In 1980 Lavelle and Wedgwood demonstrated temperatures up to $60^{\circ} \mathrm{C}$ even in the presence of irrigation other researchers have found temperature elevations up to $100^{\circ} \mathrm{C}^{35}$ While the exact temperatures of thermal injury have varied, efforts have been made in the literature to determine factors that lead to heat production and to quantify and reduce elevations in frictional heat during osteotomy preparations. Factors that have been investigated include variations among force applied, speed of drill, in vivo versus in vitro studies, varying specimen types, instrument designs, drilling methods, effect of cooling via different types of irrigation, and many others. The presence of multiple variables among the experimental setups has made the interpretation of experimental results challenging due to inconsistent measurements of parameters.

Another area of continuous research and development in implant dentistry is computer-aided surgery. In conjunction with other preoperative tools it enables surgeons to ensure precise placement of dental implants. Computed tomography (CT) technology and software have improved clinicians' abilities to plan and implement implant placement. Computer generated surgical guides can be fabricated using precise surgical 
instrumentation, thus implants can often be placed without raising a flap. A stereolithographic model created from the reformatted computed tomography (CT) data set allows the fabrication of special surgical templates that guide implants to their exact desired positions. Using surgical drill guides allows clinically significant improvement in accuracy, time efficiency and reduction in surgical error. However, like any other technology this system has its limitations. The purpose of this study is to evaluate the amount of heat generated during osteotomy with guided surgery, as this system may increase the amount of heat generated during implant osteotomy compared to conventional implant osteotomy.

\section{Statement of the Problem}

Does the use of surgical guides during guided implant surgery lead to threshold levels that may lead to bone injury? Is there a significant difference in temperature elevations during guided osteotomy drilling as compared to conventional osteotomy site preparation? Do correlations exist between $5 \mathrm{~mm}$ and $10 \mathrm{~mm}$ depth in osteotomy sites with and without the use of surgical guides? Is there a relationship between the use of surgical guides and duration of temperature elevation above threshold levels during drilling? Is there a relationship in osteotomy preparation time with or without the use of surgical guides? 


\section{Significance of the Study}

It is well known that frictional heat generated during implant osteotomy site preparations often severely elevates temperatures which lead to bone tissue injury. Thermal damage at an implant osteotomy site inhibits the regenerative response in bone healing, slowing the process of osseointegration and potentially resulting in implant mobility and subsequent implant failure. It has been shown that bone tissue is sensitive to heating at a threshold level of 47 degrees centigrade. ${ }^{26}$ The use of surgical guides during osteotomy site preparation may contribute to elevated temperatures that may be at or close to the threshold level. However, in modern implant surgery, the use of surgical guide templates fabricated from reformatted computed tomography dataset has led to many advantages in implant surgery. The amount of temperature elevation when using these surgical guides has not been evaluated and compared to conventional site preparation.

Correlation/relationship of elevated temperatures with or without a surgical guide has not been investigated. The time required for completion of an osteotomy site preparation with a surgical guide has not been compared to the time it takes to complete drilling in conventional osteotomies. 


\section{(Null) Hypothesis}

There is no statistically significant difference in temperature elevation comparing guided implant surgery and conventional site preparation. There is no statistically significant relationship between temperature threshold levels reached with or without the use of surgical guides. There is no statistically significant difference between the time required to complete an osteotomy site with or without the use of surgical guides.

\section{Definition of Terms}

\section{CAD/CAM}

Acronym for Computer Aided Design/Computer Aided Manufacturer ${ }^{1}$

\section{Computerized-Tomography (CT)}

The technique by which multidirectional $\mathrm{x}$-ray transmission data through a body is mathematically reconstructed by a computer to form an electrical crosssectional representation of a patient's anatomy. CT is used as an acronym to designate any technical field associated with this technique. ${ }^{1}$

\section{Dental Implants}

A prosthetic device or alloplastic material implanted into the oral tissues beneath the mucosal or/and periosteal layer, and/or within the bone to provide retention and support for a fixed or removable prosthesis. ${ }^{1}$ 


\section{Hounsfield Units}

The numeric information contained in each pixel of a CT image. It is related to the composition and nature of the tissue imaged and is used to represent the density of tissue.

\section{Osseointegration}

The apparent direct attachment or connection of osseous tissue to an inert, alloplastic material without intervening connective tissue. ${ }^{1}$

\section{Stereolithographic guide}

A 3-D printing method using a laser-cured resin model, generating a CAD/CAM surgical guide from reformatted CT data files via implant planning computer software.

\section{$\underline{\text { Surgical template }}$}

A guide used to assist in proper surgical placement and angulation of dental implants. ${ }^{1}$

\section{Thermocouple}

A sensor that measures temperature consisting of two different types of metals, joined together at one end. When the junction of the two metals is heated or cooled, a voltage is created that can be correlated back to the temperature. 


\section{Assumptions}

1. Bone densities are uniform.

2. CT evaluations are accurate.

3. Speed of drill is a constant $2,000 \mathrm{rpm}$.

4. The digital scale measured the force applied in $\mathrm{kg}$ directly to the surgical hand piece without load dependent energy losses or gains.

5. Twenty osteotomy site preparations do not contribute to significant wear of drill.

6. Stereolithographic generated guide used during experiment resembles that of clinical situation.

7. $47^{\circ} \mathrm{C}$ is the threshold level for osseous thermal injury.

\section{Limitations}

1. Osteotomy preparations will be performed in vitro, which may not correlate directly in vivo.

2. Forces applied to the drill are not able to be kept constant at the desired amount.

3. Bone specimens after storage may not resemble the cortical texture and density of human mandible cortex.

4. Variations may exist within osseous samples.

5. Variations may exist between individual K-type thermocouple measurements.

6. Four-channel, handheld data logger thermometer (model HH147U, Omega Engineering, Manchester, UK) allows for constant real-time temperature readings.

7. Human error exists in osteotomy preparation within and among separate surgical samples. 


\section{Delimitations}

1. Osteotomy preparations were performed by one operator.

2. Data collection and recording were performed by one personnel.

3. Computerized Tomography evaluation of osseous sample. CT evaluation provides a comparison of Hounsfield Units (HU) of equal density.

4. Surgical template was fabricated for thermocouple site drilling to ensure consistent measurements from osteotomy site.

5. Only one drill design and diameter was used in this experiment.

6. $37^{\circ} \mathrm{C}$ controlled water bath kept bone specimens at $29^{\circ} \mathrm{C} \pm 2{ }^{\circ} \mathrm{C}$.

7. Irrigation temperature was kept constant at room temperature $\left(23^{\circ} \mathrm{C}\right)$ and delivered at a flow rate of $20 \mathrm{ml}$ per minute.

8. Four-channel, handheld data logger thermometer (model HH147U, Omega Engineering, Manchester, UK) has accuracy (18 to $28^{\circ} \mathrm{C}$ Ambient) of K/J/T/E/type: $\pm\left(0.1 \% \mathrm{rdg}+0.7^{\circ} \mathrm{C}\right)-100$ to $1300^{\circ} \mathrm{C} \pm\left(0.1 \% \mathrm{rdg}+1.4^{\circ} \mathrm{F}\right)-148$ to $2372^{\circ} \mathrm{F}$. The basic accuracy does not include the error of the thermocouple.

9. K-type Thermocouple (model \# 5sc-tt-k-30-36 Omega Engineering) Standard Limits of Error: $2.2^{\circ} \mathrm{C}$ or $0.75 \%$ above $0^{\circ} \mathrm{C} ; 2.2^{\circ} \mathrm{C}$ or $2.0 \%$ below $0^{\circ} \mathrm{C}$, with a sensitivity of approximately $41 \mu \mathrm{V} /{ }^{\circ} \mathrm{C}$.

10. An iPhone timer application was utilized to ensure drilling was performed in an intermittent fashion with 2 second intervals and a 1 second rest.

11. The drill press contained a depth gauge that allowed for consistent $5 \mathrm{~mm}$ and 10 mm measurements at $T_{1}$ and $T_{2}$ respectively.

12. Thermal conducting paste was used to eliminate dead space in the thermocouple holes, ensuring more accurate thermocouple readings. 


\section{Chapter II \\ Literature Review}

\section{Background}

Historically speaking, bone drilling has been around since ancient civilization where human skulls were found with surgically perforated holes. Evidence of drilling in bone has been found in the ancient Greek, Egyptian, and Roman times. ${ }^{9}$ Although modern drilling in bone has been around since early $19^{\text {th }}$ century, it wasn't until the development of the process of osseointegration that research on bone drilling and preparation was heavily performed.

In 1952 Professor Brånemark and colleagues began studying tissue-integrated prosthetics using Vital Microscopy with the aim to define limits for clinical implantation procedures that will allow bone and marrow tissues to heal fully and remain as such, rather than heal as a low differentiated scar tissue with unpredictable sequelae. This research began in the 1960s with long-term in vivo microscopic studies of bone and marrow response to implanted titanium chambers of a screw-shape. They suggested the possibility of osseointegration, since the optical chambers could not be removed from the adjacent bone once they had healed in. They observed that the titanium chambers were inseparably incorporated within the bone tissue, which actually grew into very thin spaces in the titanium. ${ }^{14}$

For twenty years, Professor Brånemark and colleagues conducted extensive research on the parameters of tissue healing that led to clinical applications of osseointegration, which they subsequently presented for the first time in North America at the Toronto Conference on Osseointegration in Clinical Dentistry 
organized by Dr. George Zarb in 1982. The significance of this conference revolutionized the acceptance and usage of implant dentistry as we know it today. ${ }^{14}$

Brånemark and colleagues performed studies on the healing and anchorage stability of titanium tooth root implant and saw that when the implant was introduced into the marrow cavity, and allowed an adequate healing period, a shell of compact cortical bone was formed around the implant without any apparent soft tissue intervention between normal bone and the surface of the implant. They observed a direct correlation among micro topography of the titanium surface, the absence of contamination, the preparatory handling of the bone site, and the histological pattern elicited in the adjacent bone. ${ }^{14}$

Furthermore, they extracted teeth in dogs and replaced their edentulous mandibles with osseointegrated screw-shaped titanium implants. Fixed prostheses were connected after an initial healing time of three to four months without loading. Radiologic and histological analysis of the anchoring tissues showed that integration could be maintained for ten years in dogs with maintained healthy bone tissue and without progressive inflammatory reactions. Moreover, the titanium fixtures could not be removed from the host bone unless cut away and efforts to extract the implants led to fractures in the jaw bone per se, not at the actual interface. ${ }^{14}$

Furthermore, vital microscopic studies evaluated human microcirculation and intravascular behavior of blood cells at high resolution by means of an implanted optical titanium chamber in a twin-pedicled skin tube on the inside of the left upper arm of healthy volunteers. The tissue reaction was revealed by intravascular rheological phenomena was studied in long-term experiments in these 
chambers without indications of inflammatory processes. Consequently, he concluded that the principle of osseointegration may also work in humans and thus treated their first human edentulous patient in 1965. In Professor P-I Brånemark's paper titled "Osseointegration and its experimental background", published in the Journal of Prosthetic Dentistry In September of 1983, he defines the osseointegrated implant as a direct connection to the living and remodeling bone, without any intermediate soft tissue component, that is capable of providing direct transferable loads to the anchoring bone. ${ }^{14}$

In the same paper, Brånemark stresses the importance in recognizing a few principles that are valid for all implant procedures; this set of parameters has since led to the development of what's known as the Osseointegration Technique. According to Brånemark, osseointegration is dependent upon the following: Implant material, implant design, implants finish, status of the bone, implant loading conditions, and surgical technique. In regards to the surgical technique, a minimal amount of remaining bone should be removed, and the basic topography of the region should not be changed. ${ }^{14}$

In 1986 Eriksson and Adell mentioned that the osseointegration implant technique demands a minimum of surgical injury to the tissues especially with regards to thermal trauma, which is a subtype of traumatic causes of osseonecrosis. ${ }^{9,24}$ Osseonecrosis is a disorder precipitated by many conditions that result in situ bone death. Further analysis of the osseointegrative phenomena has revealed that this complex array of events may be threatened by frictional heat generated during implant site drilling. ${ }^{23,26}$ 
The extent of damage relates directly to the amount of heat that is applied to bone. The frictional heat by preparation of hard tissue gives rise to a zone of devitalized bone around the bur holes. It is imperative that when implants are inserted into bone tissues, a very gentle surgical technique is utilized to minimize the temperature rise and to create favorable conditions for bone regeneration. During repair, the blood clot, the remaining damaged cells and the damaged bone matrix are removed by phagocytosis. The periosteum and the endosteum around the bone bed respond with intense proliferation and their fibroblast and osteoprogenitor cells, which form a cellular tissue surrounding the implant. This issue is called the connective tissue callus. After one week this tissue is transformed to immature bone tissue by transformation of connective tissue cells to osteoblast, which start to produce osseous matrix. Hydroxyapatite crystals are packed in an ordered array according o the collagen fibril orientation. All this can be bone only when damage to surrounding bone has been minimized by a-traumatic bone preparation and the implant bone interface has not been subject to movement. This is achieved through a two-phased implantation procedure in which no frictional forces are applied to the implant. ${ }^{48}$

Brånemark discusses his contrasting findings to orthopedic reconstruction literature that say direct anchorage to living bone of load-bearing implants does not work in the long run. Orthopedic reconstructions that use non-biologic prosthetic materials frequently relied on implant anchorage by a space filler of so-called bone cement with self-curing acrylics (e.g. Polymethylmethacrylate). The induced surgical and chemical trauma resulting from the exothermic reaction of this material 
caused death of osteocytes at the anchorage interface. After an initial period of tremendous stability for low transmission between bone and prosthetic joint components, the damaged bone becomes resorbed and the implant is subsequently kept in place only by low differentiated fibrous tissue membrane..$^{12,14}$

Berman in 1983 said, "It has been demonstrated that during in vitro polymerization of PMMA bony cements, an exothermic reaction occurs that raises the temperature of the curing cement mass to between $100^{\circ}$ and $110^{\circ \prime}$. He further discusses that at varying thicknesses of cement, in vitro bone-cement interface temperature during polymerization of the cement mass is between $40^{\circ}$ and $70^{\circ}$, and is often responsible for the variable amounts of bone necrosis found at this interface. ${ }^{12}$ However, the precise threshold temperature for thermal osseonecrosis of human bone is still unclear. ${ }^{9}$

Regardless, temperatures ranging from $50^{\circ} \mathrm{C}$ to $70^{\circ} \mathrm{C}$ have been shown to be harmful to bone tissue due to the denaturation of alkaline phosphatates. ${ }^{44}$ In 1972 , Matthew and Hirsch recorded temperatures greater than $100{ }^{\circ} \mathrm{C}$ in 37 of 158 examinations in which there were no specific provisions for cooling. In their discussion they state, "Although our choice of 50 degrees C is arbitrary, there is evidence that damage to bone occurs at this level". ${ }^{36}$ Bonfield and Li have found that the mechanical properties of bone which had been heated to $50^{\circ} \mathrm{C}$ were irreversibly altered and attributed these changes to a reorientation of the collagen molecules associated with a weakening of the bonds between collagen and hydroxyapatite. ${ }^{46}$ Cortical necrosis and a delay in healing of surgical defects have been observed in dog femora when they were subjected to ultrasound treatment following surgery. 
The temperatures recorded ranged from $43.3^{\circ} \mathrm{C}$ to $68.7 \mathrm{C}$. Bone alkaline phosphatase is rapidly inactivated in vitro at $56^{\circ} \mathrm{C} .{ }^{\prime \prime} 3$ Still, no specific threshold temperature has been determined.

Experiments regarding this topic were conducted by Eriksson, Albrektsson, and colleagues where heated threaded titanium chambers were inserted in vital rabbit tibia to investigate thermal injury to bone. These $26 \mathrm{~mm}$ long titanium chambers had a hollow cylinder where glass rods were inserted from each end, leaving a space of only $100 \mu \mathrm{m}$ between them. The space where the two glass cylinders met allowed for microscopic observation of the bone and vascular tissue growth which occurred through a transverse canal perforating the main chamber frame. A narrower side canal ran parallel to the glass rods down to the observation area. These chambers were inserted into the cortices of rabbit tibia in the form of a screw. Vital bone and vascular tissue grew into the transverse canal over the period of 8-10 weeks at which thermocouples were inserted into the side canal and heating was applied via a heating element to temperatures of $53^{\circ} \mathrm{C}$ for 1 minute. The direct and long-term outcomes of bone blood flow and the vascular behavior of bony tissue was investigated using a specially designed microscope to observe the bone and microvascular architecture prior to and during heating, as well as the changes that occurred up to 8 weeks after thermal injury. ${ }^{23}$

Prior to heating, vessels, fat cells, lamellar bone tissues of different sizes were observed. One week following thermal injury, disappearance of pre-existing vessels, appearance of new immature vessels, and the resorption of fat cells were observed. After five weeks, vessels seemed to mature and the steady blood flow was returned. 
With all the original fat cells resorbed, new fat cells grew into the observation area and active bone remodeling with resorption and deposition was registered. The observed reactions to the described temperature reflected typical signs of thermal tissue injury. The authors concluded that "because of methodological shortcomings, we believe that studies using microangiography and/or histology as indicative methods of vascular bone survival as a rule have underestimated the actual size of tissue necrosis due to heat trauma." They further concluded the maximum time that hard tissue can tolerate ischemia is unknown. ${ }^{23}$

Following the conclusions of their study in 1982, Eriksson et al. utilized the thermal chamber technique again to analyze the response of hard tissue to temperature ranges of $47^{\circ} \mathrm{C}$ to $50^{\circ} \mathrm{C}$ at different time intervals. Fifteen rabbits were divided into three groups of five and subjected to temperatures of either $50^{\circ} \mathrm{C}$ for 1 minute (group A), $47^{\circ} \mathrm{C}$ for 5 minutes (group B), or $47^{\circ} \mathrm{C}$ for 1 minute (group C). Similarly to their previous study, microscopic observations of the bone and microvasculature were made at two-week intervals prior to, during, and after heating. ${ }^{26}$

The acute response of vasculature to the heating temperatures in all three groups $\mathrm{A}, \mathrm{B}$ and $\mathrm{C}$, were similar with initial vascular dilation and increased blood flow. The difference between the three groups was found during observation of the long-term effects. In groups A and B, previously occluded blood vessels had disappeared by approximately 10 days after thermal injury and following periods of 40-50 days, only slight vascular changes were noticed and the appearance resembled that of prior to heating and active vessels were observed in the observation area. However, in group C, 
long-term findings of vascular recovery from thermal injury seem to be more robust and a follow up at even a few days following thermal injury showed no hyperemia. At temperatures of $50^{\circ} \mathrm{C}$ for one minute, circulatory arrest of minor vessels and conclusive signs of injury were noted, therefore the authors concluded that this temperature may be the threshold of the survival of vasculature. ${ }^{26}$

Regarding the connective tissue reaction to thermal heating, no acute response was found in any of the three groups. However, darkening of fat cells was noticed at two to five days following heating, indicating the first sign of tissue injury. This darkening was proceeded by fat droplet enlargement, followed by subsequent resorption. The highest resorption of fat cells was noticed two weeks post thermal injury; however, groups A and B showed more rapid fat cell resorption compared to group C. Following this fat cell resorption and disappearance, a secondary fat cell invasion occurred in groups $\mathrm{A}$ and $\mathrm{B}$, but was not seen in group $\mathrm{C} .^{26}$

Of all the temperatures applied, no bony changes were found up to 20 days post heating. At 20-30 days groups A and B showed initial bone resorption processes. Up to thirty to forty percent bone resorption was detected toward the end of the 30-40 day interval. A common trend that was noticed was the simultaneous increase in fat cells that occurred in conjunction with bone resorption. In fact, the increase of fat cells only occurred when bone resorption was seen. Up to ninety days follow-up, fat cell dominance remained signifying the replacement of differentiated bone cells with the dominating fat cells. This bone resorption was only noticed in two out of the five test animals in group $\mathrm{C}$, with differences such as slower resorption rate and lack of fat cell invasion. Furthermore, only up to $10 \%$ of bone resorption was found in the period up to 
30 days. Nonetheless, in the other three animals in this test group, very little bone resorption occurred, thus the authors concluded that $47^{\circ} \mathrm{C}$ appeared to be the threshold level for survival of bone tissue. ${ }^{26}$

Eriksson et al summarized their findings, stating, "The present study has clearly shown that bone tissue heated to $50 \mathrm{C}$ for 1 minute or $47 \mathrm{C}$ for 5 minute will not remain as functioning bone but will become resorbed and replaced with fat cells. Heating to $47 \mathrm{C}$ for 1 minute causes fat cell injury but an inconsistent bone injury. It seems likely that $47 \mathrm{C}$ is the border temperature for the occurrence of morphologically evident bone tissue damage. “ 26

In 1984 Eriksson and Albrektsson further analyzed the effect of thermal injury on the regenerative potential of bone. Using a recently developed growth chamber technique, they studied the osteogenesis of bone in response to bone injury. The original chamber from the previous study was modified by using an implant in the diameter of $7 \mathrm{~mm}$ and $6 \mathrm{~mm}$ in height consisting of two dividable parts held together by a screw. A $7 \mathrm{~mm}$ long canal, $1 \mathrm{~mm}$ in diameter, pierces the chamber in the transverse axis. By having two separable compartments, the growth of bone into the transverse canal can be visualized by separating the two pieces when opening the joining screw. Using microradiography and conventional histology the tissue grown in the chamber was analyzed. Implants were installed in 30 rabbit tibias bilaterally and the transverse canal was situated in the cortex of the tibia. Heating elements regulated by voltage with a thermocouple was used to apply heat to the area. Three test groups were made with 10 rabbits in each, with group A at $50^{\circ} \mathrm{C}$ for 1 minute, Group $\mathrm{B} 47^{\circ} \mathrm{C}$ for 1 minute, and 
Group C with $44^{\circ} \mathrm{C}$ for I minute. The contralateral side was designated as the control group with no heat was applied to the implant. ${ }^{25}$

After four weeks the implants and surrounding bone was removed via a trephine bur. Two samples, one from the control and one from the test implant, were obtained from each specimen. The amounts of hard and soft tissue in the chambers were viewed microradiographically and then converted to numerical values to be used in comparison charts. $^{25}$

The authors' state," The inherent regenerative capacity of bone was almost completely extinguished by the thermal injury caused by exposure of the tissue to the temperature of $50^{\circ} \mathrm{C}$ for 1 minute. Reducing the heat to $47^{\circ} \mathrm{C}$ and using the same exposure time of 1 minute reduced the adverse effects on the regenerative process. Heating to $44^{\circ} \mathrm{C}$ for 1 minute caused no statistically significant observable disturbances of tissue regeneration". They went on to conclude that regenerative threshold temperatures fall in the range of $44-47^{\circ} \mathrm{C}$ and that conventional preparation technique may damage bone further than what was previously thought. ${ }^{25}$

According to Tehemar, various factors affecting heat generation during implant site drilling can be related to the operator, manufacturer, site, as well as the patient. Specifically, drilling pressure, drilling motions (i.e. graduated versus one-step drilling and intermittent versus continuous drilling), drilling speed, and time are factors particularly related to the operator. Drill design and flute geometry, diameter of the drill, irrigation system, and condition of the drill are factors related to implant manufacturers, while patient and site related factors include the patient's age and type of bone, cortical thickness, condition of the site, as well as drilling depth. ${ }^{44}$ 
Similarly, Chacon et al. outlines multiple factors that have been implicated in the production of heat during osteotomy preparation. These factors include drill speed, cortical thickness, drill sharpness, force applied to the drill, drill depth, drill design, drill diameter, graduated compared with 1-step drilling, and irrigation. ${ }^{17}$

The study by Augustin et al suggested that bone drilling parameters do not independently influence temperature rise and efficiency of drilling, but that the factors are interrelated. They propose the most significant parameters of the drill and the drilling process regarding a rise in bone temperature and the drilling efficacy. Concerning the drill, they discuss such aspects as the drill design, including the number and angle of flutes and the drill point design as well the point angle, the diameter of the drill, and drill material and wear. The factors that contribute to the wear of the drill include bone density, clogged debris released during drilling, cooling, drill material, geometry and surface treatment. Concerning the actual bone drilling procedure, aspects to consider include the drilling speed (spindle speed, rotational speed, low versus high speed drilling, etc.), drill feed rate, the power or energy of drilling, internal and external cooling, drilling depth, pre-drilling, and bone cortical thickness. ${ }^{9}$

Furthermore, Augustin et al advise critical consideration when comparing the values of temperature rise in all the various publications, considering each study's experimental setup parameters. Moreover, even single parameters have interrelated structural and principle elements that contribute to the efficacy of the bone drilling and temperature rise during drilling; consequently, analyzing even a single factor can be complex. For this reason, in this conduction of the literature review, each parameter was 
researched and will be discussed individually to help unify the conflicting variables regarding this topic. ${ }^{9}$

\section{Force}

There seems to be variation among the literature in regards to the magnitude and application of force when drilling in bone. One of the earliest papers in literature, published in 1972 by Matthews and Hirsch, applied forces of $2 \mathrm{~kg}, 6 \mathrm{~kg}$, and $12 \mathrm{~kg}$ in means to draw a comparison of different forces applied to the bony specimen. Their apparatus consisted of a specimen holder connected to an electronic dial gauge which they used to measure forces throughout each drilling procedure. They suspended weights from the specimen holder in between drillings to calibrate their set up to force measurements of $+/-100$ grams. ${ }^{36}$

To evaluate if a relationship exists between forces applied and the speed of rotation of the drill, they drilled at forces of 2,6 , and $12 \mathrm{~kg}$ rotating at speeds of 345,885 , \& 2,900 revolutions per minute in all possible combinations. Specimens were of the same cortical thickness and kept a constant temperature by using Ringers Solution. Thermocouples were placed at four measurements within $3 \mathrm{~mm}$ from the drill site, they were able to show that increasing the force decreases average temperature elevations above $50^{\circ} \mathrm{C}$. However, while $6 \mathrm{~kg}$ and $12 \mathrm{~kg}$ forces applied showed a significant decrease in elevated temperatures, the significance between $6 \mathrm{~kg}$ to $12 \mathrm{~kg}$ was not as great as that compared to $2 \mathrm{~kg}$ to $6 \mathrm{~kg}$ and $2 \mathrm{~kg}$ to $12 \mathrm{~kg}$. Furthermore, the relationship of heat generation from force were concluded to be inversely proportional (i.e. as the force increased, the temperature rise decreased). They relate the reduction in elevation of 
temperature since higher forces complete the progression of bone removal at a more rapid rate, decreasing the revolutions per minute, thus decreases the frictional heat generation in the osteotomy site. ${ }^{36}$ Although they measured the effect of speed in comparison to force applied, the factor of speed will be discussed separately.

In 1977 Hobkirk and Rusiniak had twenty operators drill holes and slots in bovine mandibles using a variety of burs to examine the interoperative differences in the amount of force generated to a custom made dynamometer that was constructed to hold the specimen. Between the six types of burs used, they found the Morse-type twist drill and a spear point drill generated less peak forces. However, since the drilling was performed 'free handed' by each clinician, variability in peak forces were recorded between 0.598 $\mathrm{kg}$ and $2.432 \mathrm{~kg}$. They suggest regardless of the efficiency of the drill used, the most significant finding was that interoperative differences is the largest variable found in rotary cutting instruments. This study, however, did not evaluate the effect of force on heat generated. ${ }^{30}$

In 1986 Eriksson and Adell described the osseointegration technique that involves the use of graduated series of drills running intermittently at low speeds (1500-2000 rpm) to avoid harmful effects to vital bone tissues. In their in vivo study, they chose five totally edentulous patients with severely resorbed mandibles, who presented radiographically with dense cortical bone to receive osseointegrated implants to conduct their investigation. To measure the heat generated during drilling, thermocouples were placed $0.5 \mathrm{~mm}$ adjacent to the drill site, $8 \mathrm{~mm}$ from the marginal crest, in a $2 \mathrm{~mm}$ deep horizontal canal within the buccal cortex. Temperature measurements were made at the final drilling sequence from a diameter of $2 \mathrm{~mm}$ to $3 \mathrm{~mm}$ at two to six sites in each jaw 
with the final bur being a $3 \mathrm{~mm}$ twist drill. The researchers found a mean initial temperature of the human mandible to be $29.2^{\circ} \mathrm{C}$ with a maximum temperature rise of $30.0^{\circ} \mathrm{C}$. Furthermore, using the osseointegration technique, drilling time did not exceed a total of five seconds. The article states "the gap between the maximum temperatures and the times that were noted in this investigation $\left(33.8^{\circ} \mathrm{C}\right.$ for 5 seconds) and the level at which Eriksson reported that the impaired bone regeneration begins to occur $\left(47^{\circ} \mathrm{C}\right.$ for 1 minute) should rather be regarded as a safety interval. It should always be remembered that slightly prolonged drilling with a little more pressure than usual, or an increased penetration depth, could easily create excessive heat in the case of dense cortical bone with low vascularity." 24

In 1995 Abouzgia and James ran an experiment with the objective to measure the effect of force on drill speed and the amount of energy used during drilling. In their study, they mention that two different recommendations exist to the amount of speed required for drilling, namely 200,000 rpm and others being 2,000 rpm. The researches questioned the free running speed versus the actual running speed which may be significantly lower. Their objective was to investigate how speed is affected by force and also to measure the energy consumed during drilling. A stryker-100 with speeds of 10,000 to $100,000 \mathrm{rpm}$, a custom made drill press, and bovine bone was used to evaluate the speed and force applied during drilling. The specific parameters used to conduct the study was a free-running speed in the range of 20,000 to $100,000 \mathrm{rpm}$ and a force applied by suspended weights ranging from 1.5 to $9 \mathrm{~N}$. They claimed that their results help shine light on the effect of force on speed during electrical drilling. At high forces, actual speed was found to be reduced up to $50 \%$ below free running speed. Their energy results 
indicate that as speed and force increase, there seems to be less energy used; as a result less heat is being generated. Consequently, since drilling time is also decreased as a result of increased force and speed, the outcome will be a total reduction in the amount of heat produced. ${ }^{2}$

In a subsequent paper by Abouzgia et al, lower temperatures were recorded at higher forces and drilling at higher speeds. Since the drilling time was significantly reduced with higher speeds and force, they conclude that the decline in temperature rise is partly due to the decreased duration of drilling. ${ }^{5}$

In 1997 Abouzgia and James again looked at the relationship of force and speed by using 1.5 to $9 \mathrm{~N}$ of force, however, keeping the speed constant at 49,000 rpm while drilling in bovine femur bone. Temperature rise was noted with forces up to $4.0 \mathrm{~N}$ however; a decrease with greater forces with subsequent decrease in drilling time was noticed. They described the total heat generated as the product of time and the rate of heat application. Since the duration of drilling was once again decreased, they attribute lower temperature with an increased application of force. ${ }^{3}$

In 1997, Cordioli and Majzoub conducted an in vitro study in bovine femoral bone with running speeds of $1,500 \mathrm{rpm}$ at $2 \mathrm{~kg}$ force. The reason of selecting $2 \mathrm{~kg}$ of force was based on averages of ten pre-tests performed by an experienced clinician. They measured at depths of 4 and $8 \mathrm{~mm}$ and parameters such as the effect of irrigation, drill types, drill diameter, and depth. ${ }^{18}$

In1996, Brisman studied the influence of changing the speed of the drill and/or the force applied to the drill on the heat generated during osteotomy preparation. $\mathrm{He}$ separated 60 samples of bovine femoral bone into four groups of 15 and defined the 
testing parameters as the following: Group 1: 1,800 rpm at $1.2 \mathrm{~kg}$; Group 2: 1,800 rpm at $2.4 \mathrm{~kg}$; Group 3: 2,400 rpm at $1.2 \mathrm{~kg}$; Group 4: 2,400 rpm at $2.4 \mathrm{~kg}$. Group 1 (low speed/low force) was the control group. He found that group 2 and 3 (independently changing one variable) increased the generation of heat; however, when both speed and force were increased, as in group 4, temperatures were harmonious with the control group, but with the advantage that significantly less time was used to reach the $7 \mathrm{~mm}$ drilling depth. Thus, it was acknowledged that increasing both the speed and the load allows the drill to cut more efficiently than at slower speeds alone, thus generating less frictional heat. They discussed clinical significance of their observations within-group 2, when the mean temperature with the $3.25-\mathrm{mm}$ bur was $51.61^{\circ} \mathrm{C}$, suggesting that clinicians may apply more pressure when they are drilling in dense cortical bone, and if drill speed is not also increased, more frictional heat will be generated. Brisman called for further studies to be conducted to determine the ideal ratio of force and speed in vivo. $^{15}$

Finally, Tehemer in 1999 states in his paper "until proven otherwise, low hand pressure that usually falls in the range of $2 \mathrm{~kg}$ should be applied throughout the complete

bony housing preparation to generate less heat." 44 While it is generally accepted that force plays an essential role in heat generation, the exact amount of force to maintain low temperature rise remains to be controversial.

\section{Speed}

In 1958, Thompson studied aseptic thermal necrosis by analyzing histologic and thermal changes in bone. In one study, extraskeletal pins were drilled in the mandible of 
dogs at speeds of 125, 250, 500, 1000, $2000 \mathrm{rpm}$ and viewed histologically. This study was followed up with another, by evaluating the effect of temperature by different speeds on the adjacent bone during drilling. Hyperemia, osteocyte degeneration, changes in bone stainability, and destruction of bone around the drill holes was found histologically as part of an acute thermal reaction. These changes increased with increasing drill speed and were higher in the 72 hour interval when compared to 24 and 48 hours. Thermal changes showed an increase in temperatures ranging from 38.3 to over $65.5^{\circ} \mathrm{C}$ with increased drilling speed. By looking at mechanical effects, penetration of bone, thermal changes, and histologic responses, $500 \mathrm{rpm}$ with the power drill was shown to be the desirable speed. The authors' state "Although this study has indicated a desirable drill speed to be $500 \mathrm{rpm}$ with power drill, it does not rule out the possibility that aseptic thermal necrosis could develop from its use. A further study of the reaction of bone to drilling at longer intervals of time at the different speeds may possibly show whether aseptic thermal necrosis could be prevented by using this drill speed." 45

In response to Thompson's publication, in 1962 Dr. S. Stephen Rafel looked at high-speed drilling and with parameters he felt should have been considered in Thompsons study. His disputes to the former study was that "no coolant was used and no preoperative temperatures were recorded; drilling time was 2.5 to 20 sec." Rafel thought the amount of heat generated by these techniques were extreme and could be minimized with irrigation and with less drill time. He conducted his experiment by using a straight hand piece with no. 8 round carbide burs and no. 703 surgical carbide fissure burs running at speeds around 350,000. Bur cuts were made in the mandibles of cadavers 
with and without irrigation and with steady pressure and intermittent pressure, using a

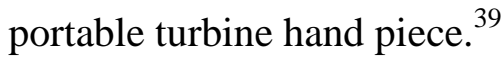

Rafel states "the technique, which causes the least rise in temperature during surgical bone bur cutting, employs a fissure bur in a hand piece driven by a high-speed engine, a continuous water spray, intermittent cutting pressures and short periods of cutting." Furthermore concluding "the longer the frictional stimulus of bur cutting is applied, the more widespread is the heat effect and the longer it takes for heat to be dissipated." They suggested 5 to 10 second drill periods with a 5 second rest to be the optimum sequence for bone cutting with burs. By using high-speed drilling, temperatures of $23.5^{\circ} \mathrm{C}$ was obtained and with an adjunct use of water spray and reduced cutting times, they suggest postoperative complications for the patient may be reduced. ${ }^{39}$

Nineteen healthy patients with partial or complete boney impacted bilateral third molars, confirmed radiographically, were used in a study carried out in 1963 by Ågren. The effect of traumatic and thermal changes of speeds of 48,000 rpm and 8,000 rpm, each used unilaterally during procedures, were compared and analyzed by looking at the extent of post-operative reactions. The general post-operative findings among the two speeds were that the facial swelling, post operative pain, and systematic reactions were regarded as similar. Although not statistically significant, trismus was found to be slightly less for the $48,000 \mathrm{rpm}$ series than the $8,000 \mathrm{rpm}$ series. Values of subjective and objective values record no differences in trauma to the two techniques. Finally, rapid instrumentation with light pressure and the decrease in duration in surgery was regarded as factors of high value in the surgical field. ${ }^{7}$ 
In 1963, Calderwood et al devised a study to compare conventional to high speed drilling due to the controversy in the current literature at the time. High speed and conventional drilling was performed on six dogs with \#557 carbide cross cut fissure bur, \#4 tungsten carbide round bur, \#5 densco diamond stones; all at high speed of 250000 rpms. Conventional drilling was preformed with \#16 steel surgical bur at speeds of 7500 rpm. Animals sacrificed at two days, one week, two weeks, four weeks, eight weeks and sixteen weeks and histologic sections were analyzed. The authors found surgical burs at conventional speeds and round burs at high speeds to show faster healing than others while cross cut fissure bur and stone healed at slower rates. The authors state "since the high speed surgical cross cut bur and conventional surgical bur have essentially the same effect on rate of healing in bone, the high speed is to be preferred because it shortens the length of the procedure noticeably and is consequently less wearing on both the patient and the practitioner."16

In 1964, an investigation by Costich et al evaluated the microscopic and radiographic changes of bone response comparing ultraspeed rotary instrument with conventional rotary instruments. Free-running speeds of 210,000 rpm and conventional speeds of 5,300 rpm, both with and without irrigation, were used to make cuts in the jaws of four adult mongrel dogs. To view the resultant histologic effects, the specimens were sacrificed and examined at one week intervals from 1 to 8 weeks. ${ }^{19}$

No evidence of bone healing was seen radiographically until five to seven weeks post-operatively; however, once apparent, the cuts made using ultraspeed with irrigation illustrated advanced degrees of healing than the other three types of cuts. Microscopically, at eight weeks there was no significant difference in the degree of 
healing in any of the four cuts. However, the cuts made using ultraspeed with irrigant showed a faster initial repair response, allowed the bone repair to progress more rapidly, and was affected less overall by the heat. ${ }^{19}$

In 1966 Boyne also evaluated the histologic and healing responses to cutting of bone and tooth extraction in ten adult male dogs in an experiment measuring the comparison of high and low speed drilling. On each side of the mandible and maxilla, either speeds of $5,000 \mathrm{rpm}$ or $200,000 \mathrm{rpm}$ were used with water coolant to section the buccal cortex. After sectioning the buccal plate and extracting the indicated teeth, the mucoperiosteal flap was approximated and sutured closed. ${ }^{13}$

Healing took place on both high and low speed areas with uncomplicated clinical healing events in all dogs; however, defects made with the high speed instruments exhibited more osseous repair at the cut surface margin at two weeks of healing. No differences were noticed at six weeks. ${ }^{13}$

"The histologic phenomena observed in this study indicated certain morphologic differences in the osseous healing responses to high and low speed sectioning; however, these differences could not be extrapolated to indicate any adverse or significantly advantageous effect on the overall healing process by either type of surgical instrumentation." While Boyne did not find a significant difference in the overall healing when comparing the two speeds, he deemed high speed instrumentation as advantageous in oral surgery procedures based on other viable literature. ${ }^{13}$

In 1968, Agren and Arwill wrap up a three part investigation on healing and postoperative reactions by means of histologic and microradiographic examination. In this study, small boney defects were created in the hind legs of nine healthy adult rabbits 
using $8,000 \mathrm{rpm}$ in one leg and 48,000 rpm in the other. The animals were sacrificed from the first to fortieth post operative day to evaluate the tissue macro- and microscopically. The author relates the findings of this study to those of previous investigations stating “a comparison between findings in Calderwood's (1964), Costich's (1964), and Boyne's (1966) investigations and the observations in this present study indicated that no substantial differences existed between the healing and bone repair in defects produced with different speed of rotation in the mandible of dog and in the tibia of rabbit, provided the burs were sharp and sufficiently cooled. Differences in anatomic characteristics of the surgical test site might exist but biologically the healing proceeded in about the same manner."6

As previously mentioned, Matthews and Hirsch examined the relationship of speed versus force in their study published in 1972. Using rotational speeds of 345,885 , and 2,900 rpm, they measured the effect of rate of rotation and drilling force on temperatures produced when drilling. In short, no significant differences in maximum temperatures were detected in which could be related to drill speed. The only notable finding was that although variations in speed did not produce a change in maximum temperature, higher rotational speeds appeared to be associated with slightly shorter drilling times. The authors of this study speculate that results of other studies regarding speed may not be adequately compared to theirs due to the type of burs used; many other studies used dental burs or smooth pins for their investigations. They state "a smooth pin has no provision for elimination of debris which is compressed between the pin and the wall of the hole. Consequently, there is a very significant increase in friction between the pin and the hole. Dental burs have different cutting characteristics than twist drills." 
Based on their initial results with force and speed, they chose $885 \mathrm{rpm}$ with $6 \mathrm{~kg}$ force to complete the remaining parameters in their experiment. ${ }^{36}$

As previously mentioned, Abouzgia and colleagues questioned free rotational speed as the actual rotational speeds may be different when drilling in bone. In their investigations $(1995,1996,1997)$, they found an occurrence of up to $50 \%$ reduction in actual speed of drilling with high forces. Consequently they concluded that higher forces with higher speeds lead to reduced temperature since less time is spent drilling in bone. ${ }^{2-4}$

While there continues to be controversy when comparing high drilling speeds to lower drilling speeds, Albrektsson in 1995 recognized that cutting tools used in highspeed drilling are designed differently than those intended for low speed drilling. $\mathrm{He}$ proposes that drilling at high speeds can be unsafe and unpredictable, stating "At 100,000 rpm the surgeon must know beforehand the exact direction and depth of penetration for his surgical intervention and he must be able to stop in time."

Eriksson and Adell, in 1986, drilling at 2,000 rpm with low intermittent pressure conducted an in vivo study on five patients and measured temperatures with a thermocouple at $0.5 \mathrm{~mm}$ from the drill site. The average drilling temperatures were only to a maximum level of $30.3^{\circ} \mathrm{C}$ and in only one patient did the temperature rise to $33.8^{\circ} \mathrm{C}$ for twenty-one seconds and yet this temperature was still below the critical threshold level of $47^{\circ} \mathrm{C}$ for one minute. ${ }^{24}$

Most recently, in 2002 an in vitro study conducted by Sharawy et al, experimented drilling in bovine cortical bone drilling at speeds of 1,225 rpm, 1,667 rpm, and 2,500 rpm using four implant systems. Although no attempt was made to incorporate the parameter of load (force applied), they suggest that drilling at higher speeds $(2,500$ 
rpm) in dense cortical bone seems advantageous in reducing the time and amount of heat generated. They also attributed a faster return to baseline temperatures with the use of higher speeds in all systems running at 2,500 rpm. ${ }^{42}$

\section{Time}

It is evident that the parameters of time, force, and speed are interrelated. For instance, Brisman's study (1996) clearly showed that increasing both force and speed together may not have decreased maximum temperatures reached, but had a benefit of shorter drilling duration. ${ }^{15}$

Eriksson and Albektsson (1983) conducted microscopic studies while drilling in rabbit tibias and related duration of thermal exposure to the extent of tissue damage. In a series of experiments modifying temperatures for one minute, they were able to show that $47^{\circ} \mathrm{C}$ appears to be the critical threshold level for osseous injury, as signs of impaired regeneration of bone was evident. To confirm this finding, a final study of heating the bone to $44^{\circ} \mathrm{C}$ for one minute showed no significant disturbances of tissue regeneration when compared to heating to $47^{\circ} \mathrm{C}$ and $50^{\circ} \mathrm{C} .^{26}$

\section{Specimen}

Many specimen types have been used to conduct investigations on heat generation while drilling in bone. Due to availability, ethical reasons, and variance of specimens, researchers have chosen bone from human cadavers, bovine femoral bones, bovine ribs, 
bovine mandibles, canine mandibles, rabbit tibias, guinea pig legs, porcine cortical ribs, among many others including bone analogs like acrylic (PMMA) ${ }^{33}$ and Delrin

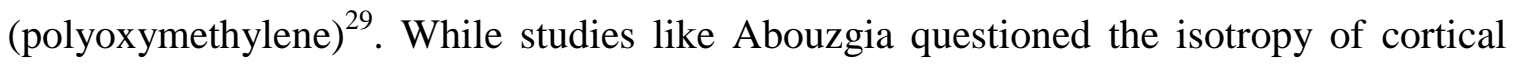
bone, they were not conducted in controlled circumstances. An independent investigation by Davidson and James (2000) was conducted in very well controlled experiment conditions improving upon the materials and methods of other prior studies to evaluate isotropy of cortical bone in longitudinal, circumferential, and radial directions. This study led to measurements that gave data regarding the thermal properties of bovine bone. They measured heat transfer in bovine femur in three orthogonal directions and found the thermal conductivity of cortical bone to be $0.56 \pm 0.039 \mathrm{~W} / \mathrm{mK}$. They found the differences in directions of thermal conductivity to be small, and concluded that bovine cortical bone can be treated as thermally isotropic. ${ }^{20}$

Since the thermal conductivity of human bone has been shown to be $0.5 \mathrm{~W} / \mathrm{mK}^{26}$ and due to the isotropy within the three directions, bovine bone has been an acceptable specimen for the measurement of elevated temperatures.

Additionally, Sedlin and Hirsch (1966) kept frozen bone specimens at $-10^{\circ} \mathrm{C}$ in periods of 3 to 4 weeks and found no significant changes in the physical properties even when frozen up to one month should they be kept adequately thawed and hydrated prior to testing. ${ }^{41}$

While the thermal conductivity and ease of storage of bovine cortical bone has rendered this specimen usable in experiments, their initial temperatures remains to be varied amongst experiments. ${ }^{41}$ divided thirty seven specimens into two test groups of $21^{\circ} \mathrm{C}$ and $37^{\circ} \mathrm{C}$. No significant difference was found in relation to maximum energy and 
energy absorbed to failure. As a result, many studies have chosen $37^{\circ} \mathrm{C}$ as the baseline temperature and attributed this to clinical conditions. However, in 1986 Eriksson and Adell found the mean initial temperature of their in vivo measurements in human mandibles to be $29.2^{\circ} \mathrm{C}\left(27.6-31.0^{\circ} \mathrm{C}\right) .^{24}$

Some studies used bovine rib since it has been demonstrated that the cortical and cancellous bone Hounsfield Units seem to be similar to that of human bone. ${ }^{22,50}$ Yacker and Klein used bovine cortical rib bone with topography of an outer cortical plate of 2 mm surrounding a medullary core and total height of specimen block was 21 to $23 \mathrm{~mm}$. Utilizing computerized axial tomography (CAT) with compatible computer software, Hounsfield density analysis showed the bovine rib cortical bone to be 1,400 Hounsfield Units and the medullary bone to be 470 Hounsfield Units. The authors claim average human mandible cortical bone to be 1,400 to 1,600 Hounsfield units, with a medullary reading of 400 to 600 Hounsfield units, thus proposing their experimental specimen was suitable to compare with a human mandible. ${ }^{50}$

In contrast, many studies have used bovine femoral bone as their experimental specimen due to the ample amount of cortical bone in the mid-diaphysis. Due to the differences in density, texture, blood supply, and thermal conductivity in cortical and medullary bone, experimental results can differ greatly between the two types of bone; heat generation seems to be more apparent in the denser quantities of bone. Furthermore, a higher failure rate has been described and accredited to elevated temperatures produced while drilling in type D1 (dense cortical) bone. ${ }^{15,42}$ Finally, Haidar et al mention "structure and vascularization play an important role in the reaction of bony tissue to the effect of heat. Well supplied with blood vessels, spongy bone dissipates the heat faster 
and has a greater capacity for regeneration than compact bone, which has a poor blood supply by comparison." 28

Regardless of the type of bone, limitation that has been challenged is the cooling effects of surrounding vasculature in vivo. Lavelle and Wedgwood question the effect of blood flow in the differences in vivo and in vitro studies; however, they speculate that capillary occlusion will likely occur when drilling. Being aware of these limitations and differences, they still consider their findings to be clinically significant. ${ }^{35}$

Three years following Lavelle and Wedgwood's speculations, Erikson and Albrektsson published their findings of vascular trauma. In regard to vascular reaction to thermal injury, they noted vascular changes and capillary occlusion when administrating thermal injury in the range of $47^{\circ} \mathrm{C}$ to $50^{\circ} \mathrm{C}$. Nevertheless, in their experiment they noticed circulatory arrest with smaller blood vessels after heating to $50^{\circ} \mathrm{C}$ and attributed this temperature to be the threshold for vascular survival. ${ }^{26,44}$ Similarly, Pohto and Scheinin noticed hyperemia at temperatures of $39^{\circ} \mathrm{C}$ to $40^{\circ} \mathrm{C}$ and blood flow occlusion at $46^{\circ} \mathrm{C}$ with two minutes of exposure time to vital dental pulp. ${ }^{38}$

While comparing their in vitro finding to operating room in vivo findings, Matthews and Hirsch state "cortical blood flow in vivo may dissipate some heat produced by drilling during operative procedures, but we do not believe that this cooling effect is significant. The cortical flow rate must be very low normally, and during drilling coagulation and occlusion of these small vascular channels probably occurs rapidly. We have recorded the temperatures when drilling human femoral cortices in vivo in the operating room on two occasions. The temp records appear identical in shape to our in 
vitro measurements, and the magnitude of the temperature elevations was similar to the experimental vales reported here." ${ }^{36}$

Consequently, due to the absence of this circulation in many in vitro studies has been investigated by many authors due to lack of relevance to actual clinical settings. For instance, Cordioli and Majzoub state "The cortical blood flow in vivo may dissipate some of the heat produced by drilling procedures. However, this cortical flow rate is low, and occlusion of the small vascular channels occurs rapidly during rotary cutting, thus reducing the cooling effect. Since all drilling procedures in this present study were carried out in cortical bone, results in humans can be extended to only type I and possibly Type II bone (classification of Lekholm and Zarb)."18

\section{Irrigation}

Another parameter that has been investigated heavily regarding the generation of heat has been the advantages and disadvantages of the cooling systems. In 1980, a histologic assessment was conducted by Fister and Gross to see effects of irrigation on bone when using surgical burs. Thirty-six vertical cuts of $1 \mathrm{~cm}$ in length were made bilaterally in the lateral aspects of the mandibles of Mongrel dogs with a surgical \#8 round carbide bur running at 1,400 rpm in an alternating fashion - one with irrigation, one without. Histological specimens were obtained and inspected at selected times postoperatively from one hour to three weeks. A main difference seen between the cuts made with and without irrigation in the early specimens was in the construction of the blood clot. In the cuts made with irrigation, the clots were firmly adhered to the bony walls and better organized. In the later histological examinations, delayed healing was 
demonstrated in the cuts made without irrigation as the bone formation in the defect was less mature than the defects made with irrigation. ${ }^{27}$

Generally, cooling systems are divided into internal and external methods of water delivery. Internal irrigation, in which cooling is delivered through the drill was proposed in 1974 by Huhule in efforts to eliminate clogging of the drill flutes by bone debris and improve delivery of the irrigant to deeper osteotomy sites. ${ }^{44}$ In Contrast, external irrigation delivers water/air to the drill from either a canula connected to the outside of the drill itself, or manually applied by a syringe.

In Lavelle and Wedgwood's publication, internal irrigation, external irrigation, and no irrigation were examined in an in vitro study using femoral bone. Ten drillings were performed for each condition in the experiment - internal, external, and no irrigation, with two types of surgical burs - round and semi-elliptical, and at 5, 10, 20, and $30 \mathrm{~mm}$ depths. Drilling was performed with constant $2 \mathrm{~kg}$ of force and at $350 \mathrm{rpm}$ throughout their study. Irrigation was delivered at $500 \mathrm{ml}$ per minute for the internal method; for external irrigation, a manual syringe directed at the bur tip was used. ${ }^{35}$

The authors of this paper showed advantageous benefits of internal irrigation compared that to external or no irrigation regardless of the cavity depth or type of bur used. They showed a reduction in the efficiency of external irrigation in deeper cavity depths. However, both external and internal irrigation was shown to have markedly less elevations in temperature than when no irrigation was used at all. Lavelle and Wedgwood conclude by saying "a major factor contributing to frictional heat in the adjacent bone during cavity preparation stems from the clogging of bur flutes by bone chips. This leads to increased torque and specific energy with increasing bone cavity 
depth. Bone chips clogging burs exert a pressure against shear traction stress. Probably one of the major advantages of internal irrigation is that it facilitates removal of bone chips from a cavity thereby eliminating or reducing the clogging of bur flutes." 35

In 1992, Sutter et al used standard instruments used in implant preparation and examined the effects of various parameters on temperature rise during drilling, as well as the scanning electron micrographic appearance of the cut bone surfaces. Their in vitro study was carried out by using 35 bovine bone samples with varying parameters such as speed (800 to 3,500 rpm), internal and external irrigation, and with two different temperatures of cooling medium $\left(5^{\circ} \mathrm{C}\right.$ and $\left.22^{\circ} \mathrm{C}\right)$. By cross-examining the parameters, they were able to show that there were no significant differences in temperature rise with internal versus external irrigation with the round bur, pre-drill, and spiral drill. However, internal irrigation was more efficient at cooling deeper drill sites than external irrigation with the trephine mills. ${ }^{43}$

Six adult female sheep were used by Haider et al to conduct a study on the effect of internal versus external irrigation on the cooling of drills around IMZ implants in spongy and compact bone using microscopy as method of investigation. Although not using standardized operative procedures, boney bed preparations were made at 1,500 rpm with an internally built cooling system or by manual cooling with a $50-\mathrm{mL}$ syringe. ${ }^{28}$

Yacker and Klein investigated temperature rise when drilling in bone comparing samples with and without external irrigation. Although they did not employ internal irrigation in their studies, they recognized it as a factor that needed to be further investigated. They contemplate that as long as the internal irrigation outlets do not clog, it may be a beneficial provision to employ during osteotomy preparation. ${ }^{50}$ 
In cortical bone, internal irrigation showed better healing in deeper levels of the osteotomy, whereas external irrigation proved superior in shallower depths. In spongy bone, superior results were obtained using external methods of cooling even in deep osteotomy sites. The authors stress the need for all means of irrigation respective of the method to cool down compact bone due to its inferior thermal conductivity compared to that of spongy bone. ${ }^{28}$

More recently, a study conducted by Benington et al in 2002 showed results that indicated there is no significant difference in irrigation system delivery in regards to cooling bone during osteotomy preparation. Their study compared the temperatures generated when drilling in bovine mandible samples when using external and internal irrigation systems. Except for changing the irrigation method, they kept all other possible variables constant, including the drill load of $1.7 \mathrm{~kg}$ - an average load that the authors claimed would be applied by a clinician, and 2-mm twist drills followed by a $3.25-\mathrm{mm}$ drill. The maximum change in temperature with the $2-\mathrm{mm}$ drills was $3.0^{\circ} \mathrm{C}$ and $3.1^{\circ} \mathrm{C}$ for the internal and external irrigation systems, respectively, and $1.34^{\circ} \mathrm{C}$ and $1.62^{\circ} \mathrm{C}$ were the maximum temperature change for the $3.25-\mathrm{mm}$ drills. They conclude by stating "the clinical benefit of using the more expensive internal irrigation systems is therefore deemed unjustifiable, on the grounds that these systems do not appear to reduce the thermal challenge to the bone over and above that of simple flood irrigation."

Other factors related to irrigation include the solution temperature as well as the rate of delivery of the irrigant to the site during drilling. Many studies regarding the generation of heat due to friction, deliver irrigant at room temperature via internal or external methods. . $^{17,18,22,36,37}$ There seems to be minimal literature on the effect of cooling 
the irrigating solution. One study that did look at this factor was done by Sutter et al in 1992. Among other parameters investigated, they evaluated the effect of cooling mediums at $5^{\circ} \mathrm{C}$ and $22^{\circ} \mathrm{C}$ on the maximum rise in temperatures during drilling. They state "with internal cooling, thermal damage to the bone did not occur with the $5^{\circ} \mathrm{C}$ or $22^{\circ} \mathrm{C}$ cooling solutions." In all cases, decreasing the cooling medium to $5^{\circ} \mathrm{C}$ decreased the maximum temperature rise. ${ }^{43}$

Matthews and Hirsch delivered three rates of forced irrigation through a drill guide that was altered to receive irrigation directly to the penetration site of the drill via two machined canals. Irrigation was delivered through the canals at rates of 300,500 , and 1,000-mL per minute in order to compare the effects of flow rate on temperature control. At all three rates of delivery, the maximum temperatures were greatly reduced in comparison to no irrigation. Moreover, it was discovered that a largest difference in affect was seen at the $500-\mathrm{mL}$ per minute rate; thus this flow rate was established as a constant variable in their other investigations. ${ }^{36}$

Other investigators delivered their irrigant at much lower flow rates, such as 40$\mathrm{mL}$ per minute ${ }^{17}, 50-\mathrm{mL}$ per minute ${ }^{28}, 70-\mathrm{mL}$ per minute ${ }^{32}$, and $90-\mathrm{mL}$ per minute ${ }^{22}$. However, irrespective of the rate of the delivery, irrigation has been documented to reduce temperatures during drilling.

\section{Instruments of Heat Assessment}

Thermocouples are sensors for the direct measurement of temperature rise during drilling. These sensors consist of metal alloys (conductors) that produce a voltage as a result of the difference between either ends of the conductors. Thermocouples are 
typically placed $0.5 \mathrm{~mm}$ or more in the site next to which drilling is performed. In Lavelle and Wedgwood, thermocouples were inserted into $0.2 \mathrm{~mm}$ cavities situated at $0.5,1.0,2.0,3.0$, and $5.0 \mathrm{~mm}$ distance from the drilling site to determine the extent of temperature rise spread. In $30 \mathrm{~mm}$ cavity depth, temperatures of $64^{\circ} \mathrm{C}$ and $66^{\circ} \mathrm{C}$ both at 5 $\mathrm{mm}$ distances from the osteotomy site was recorded with round and semi-elliptical burs respectively under no irrigation. This study shows that thermocouple distances of up to 5 $\mathrm{mm}$ are sometimes used to measure heat transmission within experimental specimens. ${ }^{35}$ Matthew and Hirsch also investigated this variable with thermocouple placements $3 \mathrm{~mm}$ depth at $0.5,1.0,2.0$, and $3.0 \mathrm{~mm}$ away from their osteotomy preparations. ${ }^{36}$ Similarly, Abouzgia and James placed up to eight thermocouples $5 \mathrm{~mm}$ deep and $0.5 \mathrm{~mm}$ apart in transverse and longitudinal directions of their specimen. ${ }^{2}$ Furthermore, Misir et al placed three thermocouples vertically from the prepared site to depths of 3,6 , and $9 \mathrm{~mm} .{ }^{37}$ Regardless of the methods used, most thermocouple channels are sealed with the use of wax or silicone based paste, or even sometime secured in place with small wooden wedges to minimize saline entry or movement during drilling. Nevertheless, $0.5 \mathrm{~mm}$ of distance from the osteotomy site has been the most common distance implemented in the literature. Eriksson and Adell placed $0.5 \mathrm{~mm}$ thermocouple holes in vivo in five patients and recorded real-time cortical bone temperatures during drilling. ${ }^{26}$

Benington et al described a method of measuring temperature which is noninvasive and has been utilized since the 1960's - infra-red thermography. They explain the main limitations of using thermocouples for temperature measurements are that they only indicate spot thermal changes at the sites chosen to place to thermocouples, they must be close to the drill site interface, and they require a separate procedure for the 
insertion of the thermocouple. Also, "surface contact may be a source of error in measurements using thermocouples since all thermocouples must make contact with the surface, not necessarily in the correct plane, and therefore may alter the localized surface temperature". 10

In contrast, thermo-imaging allows the temperature changes to be recorded and followed continuously throughout the drilling procedure. Additionally, two-dimensional color images allow for easy identification of the point of maximal temperature increase and the thermal spread through bone. Possibly the most advantageous feature of thermography is that measurements can be made without damaging the specimen since additional holes do not need to be drilled in specimens like that with thermocouples. ${ }^{10}$ However, disadvantages of thermography include that it is indirect and absolute values of temperature in particular point of bone could only be extrapolated; thus thermocouples may still be required for efficient thermal measuring. ${ }^{9}$

Another method recently described in literature to record temperature rise is with the use of fluoroptic thermometers. Fluoroptic thermometer probes can be used with irrigation and are "immune to electromagnetic and radiofrequency noise, no temperature drift or recalibration are required, are much more robust than thermocouple and are ideally suited for hostile environments."34

\section{Modes of Drilling}

To widen an osteotomy site, graduated and one step drilling have been proposed to accept the exact diameter of an implant after drilling. In an in vivo study, Albrektsson et al recommended the placement of screws for Richards' plates at 20,000 rpm with a 
single twist drill to the final diameter in one single step. Comparably, the process of osseointegration technique calls for the use of graduated series of drills running in an intermittent fashion, widening the side with each subsequent drill, removing minimal bone, hence minimizing the amount of thermal and physical trauma to the site.

Eriksson and Adell described the method of using graduated series of drills in order to achieve the osseointegration technique in their publication in 1986. They prepared in vivo osteotomy sites using a graduated series of drills and successively enlarging the diameter of the implant, using intermittent and low force at a constant speed of $1500-2000$ rpms. As mentioned earlier, they suggest lower temperature rise in bone by using progressive drill sizes because it removes only small quantities bone as the site are already cut by the preceding burs. Moreover the removal of the drills during surgical preparation allows for the escape of bone cut and access for irrigation fluid. ${ }^{24}$

Likewise, Yacker and Klein carried out four investigations, each with and without external irrigation at various drilling depths: 1) Pilot drill alone, 2) 2-mm bur without pilot drill, 3) 2-mm bur with pilot drill, and 4) 2-mm bur increasing to $3 \mathrm{~mm}$ bur. In all situations, external irrigation produced considerably less amounts of heat than when no irrigation was used.

Due to the bone specimen used, drilling depths were in various densities of bone thus for generalization purposes, we are only considering drilling depths at $8.5 \mathrm{~mm}$. This $8.5 \mathrm{~mm}$ bone depth apparently consisted of $2 \mathrm{~mm}$ of outer cortical bone and $6.5 \mathrm{~mm}$ of medullary bone. Increasing the osteotomy site from $2 \mathrm{~mm}$ to $3 \mathrm{~mm}$ produced less heat than when the $2 \mathrm{~mm}$ bur was used alone, without the pilot drill. However, the lowest 
temperatures were recorded when using the $2 \mathrm{~mm}$ diameter bur following a pilot drill. Thus, indicating that smaller amounts of bone removal in graduated drilling sequence decreases elevations of frictional heat generation. ${ }^{50}$

Similarly, Matthew and Hirsch investigated the effects of preliminary drilling by using a $2.2 \mathrm{~mm}$ drill to determine its effect in reducing the maximum temperatures and the durations of temperature elevation. Holes were first drilled with a $2.2 \mathrm{~mm}$ drill at 885 rpm and at $6 \mathrm{~kg}$ force. The holes were then enlarged to $3.2 \mathrm{~mm}$ with a standard drill at the same drilling speed and force. Then control holes were made in the same specimens at the same drilling speed and force using only the 3.2-mm drill in one-step widening.

Matthew and Hirsch found similar temperature elevations (below $50^{\circ} \mathrm{C}$ ) in the 2.2-mm pre-drill when it was used alone, and when enlarging the $2.2 \mathrm{~mm}$ hole to $3.2 \mathrm{~mm}$; however, the $3.2-\mathrm{mm}$ drilling showed marked temperature elevations above $100^{\circ} \mathrm{C}$ when it was used in one-step drilling.

Similarly, other methods that involve lengthening of the osteotomy site involve methods of intermittent versus continuous drilling. "It is known that continuous drilling prevents escape of cut bone chips and access for the irrigation fluid, thus causing clogging of the twist drill bit and a substantial increase in cutting energy and temperature generated." Cordioli \& Majzoub (referenced Wiggins \& Malkin as well as Adell \& Lekholm) They infer that less temperature differences should occur under clinical conditions when a pumping motion is used with the twist drill.

Wachter and Stoll investigated adequate bone cooling on the deeper bone layers in vitro and in vivo investigations. For their in vitro investigation, thermocouples were placed at depths of 2, 4 and $6 \mathrm{~mm}$ in bovine mandibular bone. Thermocouples were 
placed into grooves positioned in the blade of the saw and held in place with cyanoacrylate adhesive. While in their in vivo investigation, disposable saw blades were prepared as previously mentioned and 105 measurements were collected using irrigation in 28 adult sheep mandibles. Disposable saw blades were used prepared as mentioned above. Using irrigation, a total of 105 measurements was evaluated and a mean elevation of temperature of $11^{\circ} \mathrm{C}$ was observed. ${ }^{47}$

For the in vitro portion of their study, 30 measurements were performed under continuous load, temperature of $20^{\circ} \mathrm{C}$ to $100^{\circ} \mathrm{C}$ with irrigation was observed. Interestingly, continuous load without irrigation resulted in similar temperatures to the continuous load with irrigation. However, when intermittent load was applied, the mean temperature was only $45^{\circ} \mathrm{C}$. It is apparent that intermittent loading allowed irrigation solutions into the cut bone and adequately cool it while the frictional forces were being applied. When intermittent load was applied without irrigation, maximum temperatures of $117^{\circ} \mathrm{C}$ were observed rendering air as an unsuitable coolant. Furthermore, Wachter and Stoll found that "if irrigation starts during intermittent sawing procedure, a drop in temperature from a mean of $125^{\circ} \mathrm{C}$ to less than $40^{\circ} \mathrm{C}$ is observed, even if the applied load is increased."

\section{Drill Wear}

An armamentarium factor that is related to thermal injury to bone during osteotomy preparation is wear and the dullness associated with surgical drills after multiple uses. Repeated drilling, sterilization, and cleaning and scrubbing of burs may 
lead to wear and tear of the cutting edges of drills thus leading to higher friction during drilling.

One of the earlier studies that investigated the effect of wear on heat generation during drilling was that of Matthews and Hirsch. They compared the maximum average temperatures and the amount of time of elevation above $50^{\circ} \mathrm{C}$ for new and worn drills that had been used for more than 200 drillings. Unanimously at all thermocouple positions, the holes drilled with the worn drill caused much higher temperature elevation and longer duration of temperature elevations. Finally, they discuss "in agreement with Patterson we feel that bone drill should be considered as an expendable item to be sharpened or replaced at the first visual indication of dullness, when the drill fails to progress rapidly, or after approximately 40 holes.”

Abouzgia and James, following the recommendations of Matthews and Hirsch, replaced their drills at the first sign of dullness after frequent examination of the cutting edges. They found 20 to 30 tests could be used for each drill. ${ }^{2}$ Similarly, a study conducted by Cordioli and Majzoub found no significant difference when comparing mean maximum temperatures of three sets of ten drillings. Changing the bur after the $30^{\text {th }}$ use appeared to keep the amount of drill wear from being a variable in their investigation.

In an in vitro study, Brisman used a series of three burs of increasing diameters to prepare 60 osteotomies in four test group conditions. They used a new set of burs for each group - thus four new burs were utilized in the study.

Jochum and Reichart assessed drill wear using scanning electron microscopy (SEM) in their in vitro study regarding cannon drills. They explain that "Cannon drills 
may be used for final enlargement of implant sites, and because drilling temperatures decrease with the distance from the cutting edge, those drills need to provide low drilling temperatures even more than, e.g. pilot drills". They made 245 measurements; drills were divided into three groups that were treated differently after preparations: by disinfecting with one of two solutions followed by autoclaving or by cleaning with distilled water only. They grouped sets of 10 drillings together for comparison purposes and found that only drills used more than 40 times had a significant increase in temperatures. They also found that only the two groups that had been autoclaved showed an increase in width of the cutting edges. Although their SEM results showed some dulling of the drills after autoclave sterilization, there did not seem to be a resultant increase in drill temperatures.

An interesting in vitro study conducted by Sutter et al in 1992 examined drill wear by using scanning electron micrographs to observe the appearance of the bone surface of the implant bed instead of the appearance of the actual drill. Their results showed "that fine bone structures of the implant bed were still achieved after multiple uses of the instruments" and that a drill could be used approximately twelve times and still produce smooth, clean, crisp cuts with a preservation of fine bone structures. They also state that "No visible degradation occurred from multiple uses of the instruments."

Accordingly, Harris and Kohles study on mechanical and thermal fatigue of various dental drills supports that individual drill design strongly affects drill performance and that the drill design itself may affect rate of wear. They quote an establishment from Yacker and Klein's study in their paper regarding the duration of "cutting time is related to the surface treatment and composition of the bur, suggesting 
that specific bur characteristics affect wear." Harris and Kohles discuss the results of their study by stating "Although each drill successfully removed material from the drilled substance throughout testing, the reaction stresses were altered with accumulated loadings. This increase in the stress state may be an indicator of fatigue damage and degradation of the cutting edges. This response does not suggest that the drills will eventually fail-only that there is an increase in the mechanical resistance with each subsequent."

In 2006, the study by Chacon et al demonstrated that implant drills had a tendency to generate more heat with increased use. They also evaluated the drill design as a factor in drill wear by comparing three implant systems: A (triple twist drills with a relief angle), system B (triple twist drills without a relief angle), and system C (double twist drills with a relief angle). Keeping all other possible factors constant, they found that the implant drills that contain a relief angle appeared to stay below the critical threshold temperature; however, with repeated drilling all implant drills generated more heat. From their results, they suggest that 25 uses of a drill should be safe to stay within the accepted temperature parameters.

Ercoli et al concurs that repeated drill use progressively increases drill wear and leads to decreased cutting efficiency and increased frictional heat. They completed an in vitro study on bovine ribs using twenty individual drills of ten different types to cut 100 osteotomy preparations each. In general, the hardness of the drill was a large factor in the amount of wear and tear the cutting edges accrued. The harder of the twist drills with external cooling successfully completed the 100 cuts and exhibited relatively little damage along their cutting edges. However, the drills of the same design, only with a 
decreased hardness/composition of the drill, were unable to sustain its shape and sharpness and lead to excessive drill wear and fracture. Additionally, they state "of the 20 individual drills tested, most showed quite consistent performance during extended use, with 12 successfully completing all 100 stimulated cuts. For all of the drills, the average temperature rises at both thermocouples sites were well below values of clinical concern."

"Although significant surface wear was noted for most drills when comparing SEM photographs before and after use, these changes did not produce large variation in the recorded bone temperatures. This is in spite of the fact that different drill designs, materials and the amount of use did have significant difference in the removal rate as previously discussed. This shows that external irrigation and drilling methods employed in this protocol, i.e. reproduction of a pumping motion were significantly effective in most instances to suppress excessive heating of the bone for any of the drills tested." Lastly, Ercoli concludes that "drill design, material, and mechanical properties significantly affect cutting efficiency and durability. These factors should be considered during implant drill design and their combined effect assessed during testing on bone tissue.

\section{Drill Guides}

Finally, the use of surgical drill guides in recent years has been implemented more commonly, particularly with the placement of multiple implants for the edentulous arch. Although surgical guides could possibly be a variable that may contribute to the elevation of temperature as a result of frictional heat, their efficacy and advantages has been 
documented in the literature. Progression in the placement of implants in dentistry has led to a revolution of various guided surgical placement procedures that has changed the way implants are surgically placed.

With advancements in three-dimensional technology and their availability, dental surgeons can diagnose, treatment plan, and execute surgical techniques by using computer software. 3-D imaging now allows us to view anatomical limitations and restraints to implant placements. More importantly it allows surgeons to evaluate the quality and quantity of osseous structure even prior to patient consultation. Currently the innovations of Cone-beam CT as opposed to Spiral or helical CT, imaging is now more readily available to most dental surgeons and restorative dentists. Cone-beam CT with reduced exposure, lower price, smaller machinery and smaller slice increments has become routinely used in the implant world. ${ }^{31}$ Based on our experience, we have seen that patients gravitate toward advantages of quicker surgeries, possibilities of flapless surgery, quicker healing times, reduced pain and swelling, and possibility of immediate loading via a provisional prosthesis fabricated via this technology prior to surgery.

Computer-assisted guidance can fabricate surgical guides with the aid of CAD (computer aided design)/CAM (computer aided manufacturing) technology. CAM methods for implant applications include 3-D-printing techniques or computer-driven model drilling. These guides are then used during surgery in the hope to improve accuracy, confidence, and rapidity. CAD/ CAM surgical guides require 3-D CT scanning and computer software programs that assist in diagnosis and planning.

$\mathrm{CAD} / \mathrm{CAM}$ printing methods can generate a guide made up of a Stereolithographic material fabricated via laser cured resin model. West Virginia 
University Department of Prosthodontics currently utilizes SurgiGuide® (Materialise, Glen Burine, MD), which is a system that uses stereo-lithography to fabricate surgical guides. The process begins with missing teeth or structures that are duplicated in a radiopaque material which is embedded in a radiographic template for the patient to wear during the CT scanning process. The software SimPlant® (Materialise, Glen Burine, MD) allows virtual planning with the final restorative outcome and plans in mind. Once the plan is approved a computer-controlled laser then cures small layers of a liquid polymer in sequence of small slices until the model is finalized. Metal sleeves are inserted into the guide followed by production of a series of guides to accommodate sequential drill sizes. Depth control and capability of interchangeable surgical tubes are all possible with this system. With the aid of rapid prototyping, a restorative plan can be initiated and executed to the end. Patients with anatomic limitations, the ones in need of multiple implants placed, or even inadequate amount of osseous structures can benefit greatly from advanced guided surgery.

Most 3-D software systems offer similar functions and offer three choices of surgical guides depending on the patient's oral anatomy: tooth-supported, mucosasupported, or bone-supported. The tooth-supported guide is positioned directly over the teeth for partially edentulous cases. With this type, implants can be inserted with high accuracy since the teeth help stabilize the guide in place. This guide is extremely useful in tight dental spaces and areas where flapless surgery may be needed. Next, the mucosasupported guide is mainly used for fully edentulous cases. The guide is anchored in place with extra pins placed into the bone facially to the planned treatment area. This technique can offer multiple implant placements and even immediate loading of the full edentulous 
arch when all the steps are followed carefully and accurately. Finally, the bone-supported guide is suitable for fully and partially edentulous areas where extra visibility is needed. With adequate amount of osseous structures, a full mucoperiosteal flap is elevated and the guide is anchored to the underlying bone with pins and screws. Effective guide positioning, stable anchoring, and flap design are critical for the proper placement of the guide within the surgical site.

Most studies that have implemented surgical guides during dental implant surgery have evaluated it's accuracy with implant placement. ${ }^{40}$ It is no surprise that utilizing a surgical guide can decrease operator error in proper implant location placement and angulation. A literature review by Jan D'haese et al reviewed 31 papers from 1988-2009 that utilized computer-designed Stereolithographic surgical guides for implant placement and evaluated the associated accuracy and complications. ${ }^{21}$ Based on the literature review, most authors reported some deviation between pre-operative plan and postoperative placement. The author of the review suggests guided implant surgery is not as accurate as it is perceived to be when utilizing computer designed Stereolithographic surgical guides; however, does state that guided implant placement has a tendency to show smaller deviations than when implant installation is completed manually. Since the start of guided surgery various articles have questioned the accuracy of such guides and recommendations have been made to the profession.

However, very few articles in the implant literature have looked at the amount of heat generated with guided implant surgery. Initially, in 1972 Matthews and Hirsch investigated the effect of surgical guides on the amount of heat generation during implant drilling and found no significant difference in maximum average temperatures above 
$50^{\circ} \mathrm{C}$ was observed with or without the use of surgical guides. However, the authors recommend a forced irrigation at the rate of $500 \mathrm{ml}$ per minute pointed at the insertion point of the drill to allow irrigation into the surgical site. Because this was unable to be accomplished by means of manual irrigation, they altered their drill guide with two channels to allow the forced irrigation to flow to the osteotomy site.

In conclusion, they recommend "we feel that irrigation should be used whenever drilling in cortical bone. If a drill guide is used, we would recommend that the guide be removed or backed up the shaft of the drill after the hole has been started so that the irrigating stream may be directed to the site of penetration of the cortex. Although we had anticipated that the use of a drill guide would be associated with greater temperature elevations, our studies failed to substantiate this impression."

A recent in vitro investigation conducted by Misir et al compared two implant systems with and without the use of surgical guides. By the use of a surgical hand piece and a modified drill press, $2 \mathrm{~kg}$ of force and a drilling speed of 1,500 rpm was used to compare system A (only external irrigation) and system B (internal and external irrigation). For each system, a total of 40 samples were drilled - half with use of a surgical guide and the other half without (conventional drilling). Thermocouples were placed in a vertical fashion 3,6, and $9 \mathrm{~mm}$ deep at $1 \mathrm{~mm}$ away from the osteotomy site.

Although the maximum temperatures were not above the critical threshold of $47^{\circ} \mathrm{C}$, they did find a difference in the temperature elevations when using the surgical guide as opposed to when they did not. They summarize their results as "the mean maximum temperatures at the depths of 3,6 , and $9 \mathrm{~mm}$ using surgical drill guides were $34.2^{\circ}, 39.7^{\circ}$, and $39.8^{\circ} \mathrm{C}$, respectively, although without using surgical drill guides the 
values were $28.8^{\circ}, 30.7^{\circ}$, and $31.1^{\circ} \mathrm{C}$. A statistically significant difference was found at the depths of 3,6 , and $9 \mathrm{~mm}$ between using surgical drill guides and classical drilling procedure."37

\section{Chapter III}

\section{Materials and Methods}

Fresh bovine femoral cortical bone was obtained from a local slaughterhouse (Fig.

1). The samples were kept cool in ice at $0^{\circ} \mathrm{C}$ until the next day where they were taken to the radiology department at West Virginia University for a spiral CT scan (Fig. 2). Using a handsaw, the mid-diaphysis of the femoral bone was sliced radially in $1 \frac{1}{2}$ inch sections and each side of the section labeled A or B depending on the direction from the epiphysis. The slices were wrapped in wet cloth sheets, sealed in a zip lock bag and stored in ice until used.

A cubic water bath $9 \times 10 \times 5$ inches was constructed by bonding $0.220 "$ thick acrylic

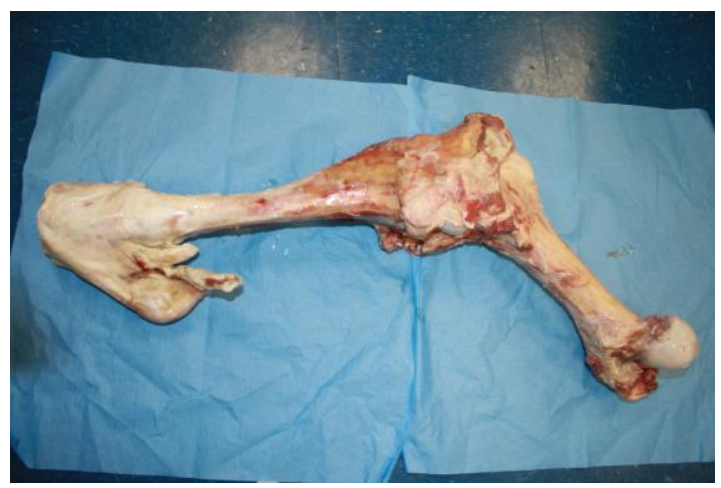


sheets (Plaskolite, Inc., Columbus, $\mathrm{OH}$ ) together with acrylic resin and reinforcing the outer sides with aluminum corner trim by fixation with six mini screws on each side. (Fig. 3) Finally all Fig. 1 Fresh bovine leg bone prior to CT scan, sectioning and freezing.

internal edges of the water bath were sealed with clear waterproof silicon. To maintain the water bath temperature at $37^{\circ} \mathrm{C}$, two submergible aquarium heaters 100 Watts Model \# 015905061018 (Franklin, WI) were secured with suction cups to the inner walls of the water bath assembly.

A Craftsman 10" Bench Drill Press model \# ZJ4113Z was modified to accept an acrylic block which contained a WI-75 E/KM surgical contra angle hand piece 20:1 model \# 10207557 (Zimmer Dental, Carlsbad, CA). (Fig. 4 and 5.) The solid acrylic block was fabricated with Biocryl Ice acrylic (Great lakes orthodontics Tonawanda NY) to the dimensions of $30 \times 40 \times 90 \mathrm{~mm}$. 
A paralleling jig (Fig. 6) was fabricated to orient and secure the contra angle hand piece to the acrylic block so that the twist drill would be parallel to the long axis of the drill press.

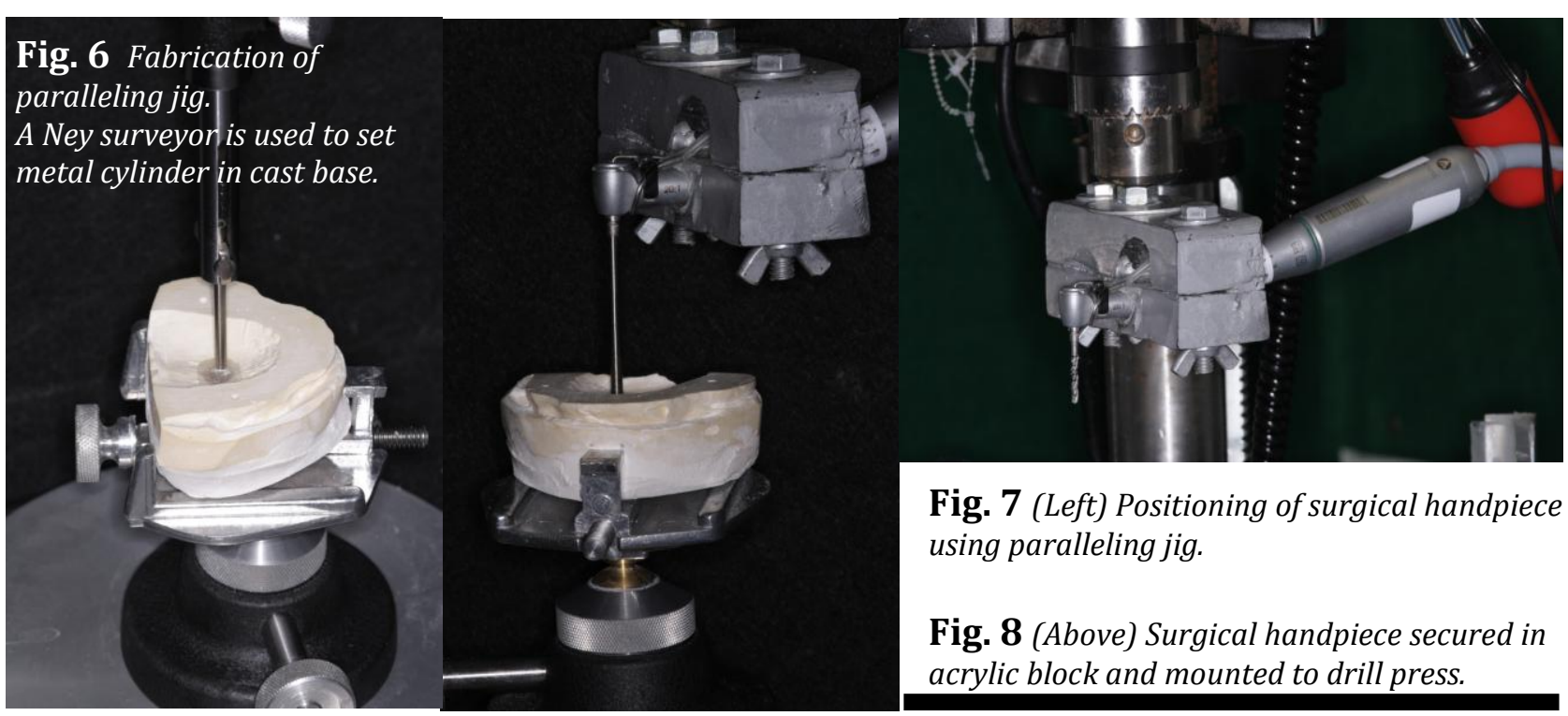

To construct the jig, a 2 inch, $2.3 \mathrm{~mm}$ diameter metal cylinder (obtained from a local hardware store) was placed into the vertical arm of a Ney surveyor and held in place with the vertical arm screw. A pre-made stone cast platform was secured onto a Ney surveying table and placed on the surveyor base. The vertical arm was lowered so the attached metal cylinder was sturdily placed into a pre-made hole in the stone model. Acrylic resin was flowed around the metal cylinder, affixing it to the cast. Once cured, the vertical arm screw was loosened leaving the metal cylinder attached to the stone base and perpendicularly positioned to the horizontal plane. The jig's $2.3 \mathrm{~mm}$ cylinder accommodates the placement of the $2.3 \mathrm{~mm}$ twist drill inserted into the hand piece.

With the acrylic block now attached to the drill press chuck, the hand piece was inserted through the opening of the acrylic block and a $2.3-\mathrm{mm}$ twist drill was inserted into the contra angle. The twist drill was lowered completely into the paralleling jig's 
metal cylinder thus ensuring appropriate alignment of the handpiece into the acrylic block (Fig. 7). While securely maintaining the proper alignment of the jig and twist drill assembly, the surgical hand piece was set in place by relining the opening of the acrylic block surrounding the contra-angle (Fig. 8).

The surgical handpiece was connected to a Zimmer® Surgical Motor System with a $1.8 \mathrm{~m}$ motor cpl cable. The foot pedal was also connected to the motor and motor-speed set to 2,000 rpm. A $2.2 \mathrm{~m}$ one-piece disposable irrigation tube was attached to a saline bag that was suspended to the ceiling tiles above the drill press. Saline at room temperature was pre-determined to deliver an irrigation flow at a rate of $20 \mathrm{ml} / \mathrm{min}$ when the delivery bag was suspended above the drill press..

A WeighMax Xtro 150 Digital Scale, model \# W4820 (Scales Galore, Brooklyn, NY ) with Sensitivity of $0.05 \mathrm{~kg} / 0.11 \mathrm{~b}$ and dimentions of $11.25 " \mathrm{x}$ $1.25^{\prime \prime} \times 12 "$ was placed on the drill press table, underneath the water bath assembly, to measure the load applied to the experimental specimen.

A leveler was used to ensure each section of bone was parallel to the horizontal plane before securing to a surveying table (Fig. 9). A $1.5 \mathrm{~mm} \mathrm{x}$ $17 \mathrm{~mm}$ black twist drill model \# 31278 (Nobel

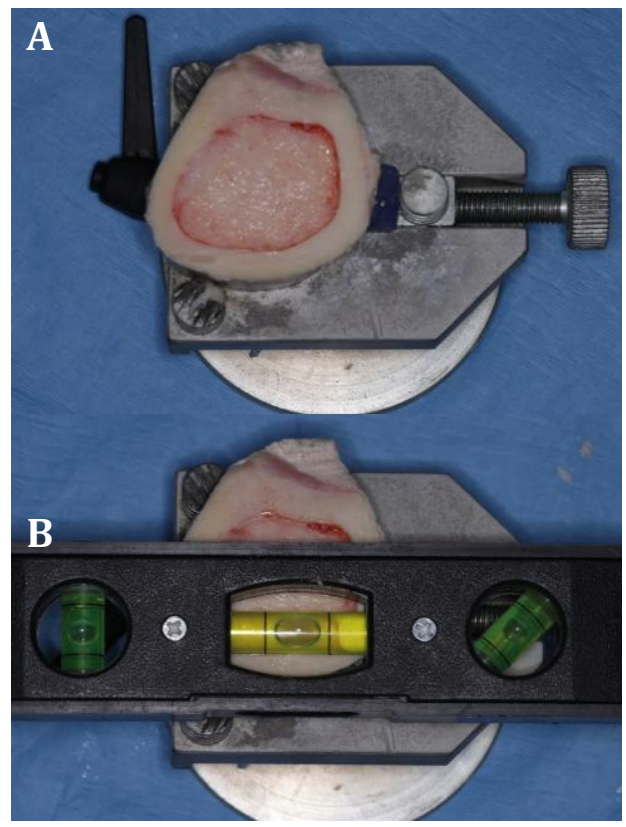

Fig. 9 Positioning of the bovine specimen prior to drilling. The specimen was secured on a surveying table (A). A level was used on the bone specimen so drilling surface is parallel with horizontal plane (B). 
Biocare $^{\mathrm{TM}}$, Switzerland) was used to drill two $1.5 \mathrm{~mm}$ drill holes at $0.5 \mathrm{~mm}$ distances from the edges of a $2.3 \mathrm{~mm}$ divot created by twist drill model \# SV $2.3 \mathrm{DN}$ (Zimmer Dental, Carlsbad, CA).

A $2 \mathrm{~mm}$ thick clear acrylic sheet was used as a template to ensure consistent $0.5 \mathrm{~mm}$ distance to the osteotomy site. In doing so, an initial $2.3 \mathrm{~mm}$ hole was drilled into the acrylic sheet. Using a digital caliper, two $1.25 \mathrm{~mm}$ measurements were made from the edges on either side of the initial hole, and this measurement was used as the center for the $1.5 \mathrm{~mm}$ thermocouple holes (Fig. 10). The template was used to deepen the thermocouple holes to 5 and $10 \mathrm{~mm}$ depths and labeling them $\mathrm{T}_{1}$ and $\mathrm{T}_{2}$, respectively.

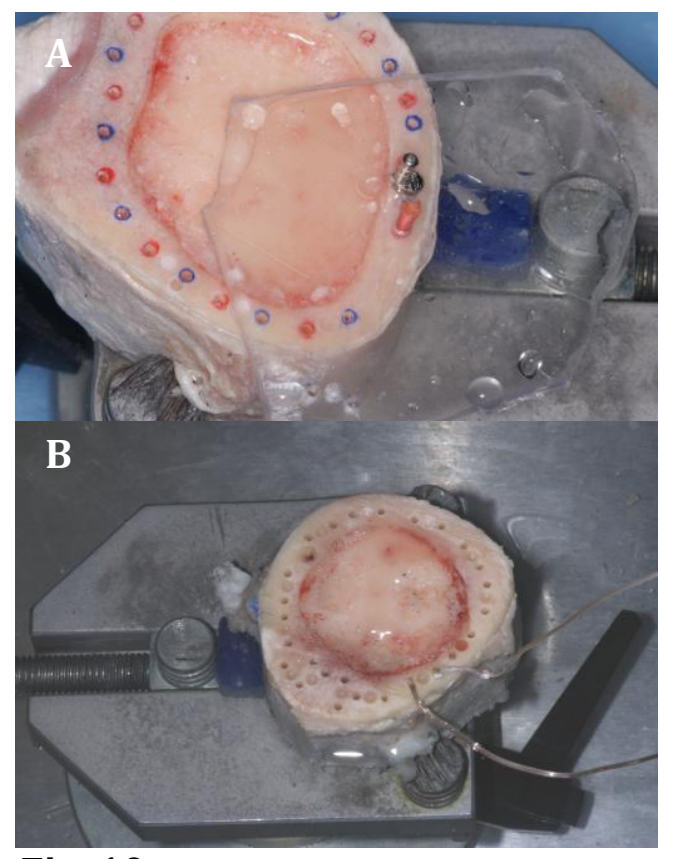

Fig. 10

Clear template guide is shown for drilling thermocouple holes and $T_{1}$ and $T_{2}$ holes marked accordingly for quick recognition. Pins are placed through the template into the thermocouples holes to secure the template in place to drill the divot (A).

After thermocouple holes and divots are completed, thermocouples are placed and secured with wax (B).
Furthermore, the template was secured flat to the bony specimen by the insertion of $1.5 \mathrm{~mm}$ pindex pins through each thermocouple hole. Subsequently a $2.3 \mathrm{~mm}$ Zimmer® twist drill was used to create a $0.25 \mathrm{~mm}$ divot hole to be used for the future osteotomy preparation. The pre-created divot hole is critical to ensure proper placement from the thermocouple holes since most drills bend and slide at initial bone contact. We found this method to be very efficient since drilling was performed in the same manner repeatedly obtaining equal dimensions from the center of the $2.3 \mathrm{~mm}$ drill. Using the depth gauge feature of the drill press, repetitive $5 \mathrm{~mm}$ and $10 \mathrm{~mm}$ depth holes 
were made for the thermocouples $\mathrm{T}_{1}$ and $\mathrm{T}_{2}$,

K-type Ready-Made Insulated Thermocouples with Kapton PFA, Glass Braid Insulation and Molded Connectors model \# 5sc-tt-k-30-36 Omega engineering (Stamford, Connecticut) were coated with thermal conductivity paste Omegatherm product \# OT-201-1/2 (Omega engineering) and inserted into the 1.5mm holes, secured in place with dental wooden wedges, and sealed with blue periphery wax (Heraeus Kulzer Inc., Armonk, NY) to act as a sealant and to prevent irrigation fluid from entering the hole, which could affect thermocouple readings directly. The two thermocouple Molded Connectors were connected to handheld data logger thermometer Model \# HH147U (Omega engineering) and readings were observed at T1 and T2.

After thawing in the water for an average of one hour, the inferior $2 / 3$ portion of the bony specimen was inserted into the water bath and the temperature of the thermocouples were monitored until the bone reached temperatures of $29^{\circ} \mathrm{C} \pm 2^{\circ} \mathrm{C}$ at $\mathrm{T}_{1}$ and $30^{\circ} \mathrm{C} \pm 2{ }^{\circ} \mathrm{C}$ at $\mathrm{T}_{2}$. Drilling was randomly performed using both internal and external irrigation with either conventional drilling or with the use of a surgical guide.

Before conventional experimental drilling (Fig. 11) was commenced, thermocouples were secured in appropriate holes, by aforementioned method, the scale was set to zero by pressing the tare button, and the irrigation roller clamp was turned on to allow adequate irrigation flow to the drill. Drill times were recorded when the drill contacted bone and immediately after drilling was stopped. Drilling was performed using an iPhone application called seconds set at 3-second intervals to standardize intermittent drilling at 2-second drill intervals with a 1-second rest. 
For guided experimental drilling, Stereolithographic guides from routine surgeries were sectioned and the metal sleeves with its surrounding acrylic frame were retrieved from the whole template. In this experiment, Zimmer® guided surgical protocol involving tube adaptor and metal sleeves was followed by inserting the Zimmer® T2.3 $\mathrm{mm}$ tube adapter into the metal sleeve. (Fig 12) The $2.3 \mathrm{~mm}$ twist drill was inserted through the T2.3mm tube adaptor/metal sleeve assembly and securely placed into the precreated divot hole by raising the drill press table until fully engaged to the bone. Finally, once the thermocouple holes were sealed with wax, the assembly was lowered and secured in place by adapting handmixed clear acrylic resin around the metal sleeve's acrylic frame. Once acrylic was cured and thermocouple readings reached the proper baseline temperatures, guided drilling was initiated in the same manner as described for conventional experimental drilling.

The USB Interface for the handheld data logger allows computer data logging via Omegasoft Ver.V1.0.12

Software for Data logger Thermometer HH147U (Omega Engineering). The software was used on a laptop computer running Microsoft Windows 7.

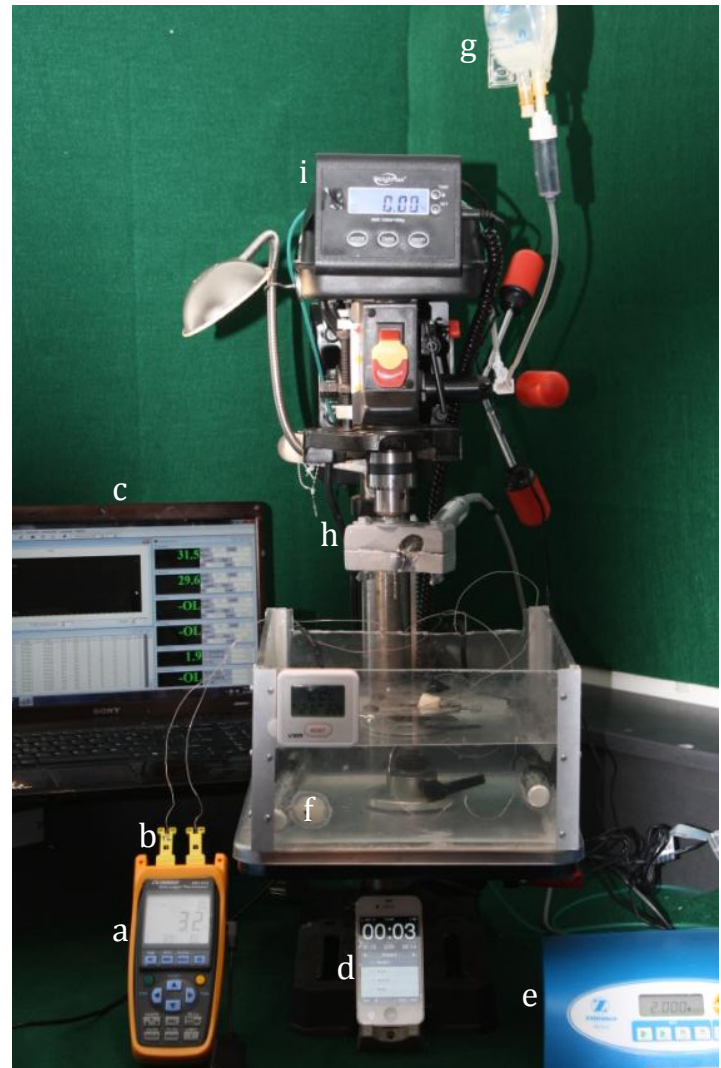

Fig. 13 Complete experimental set up: data logger(a), $K$-type thermocouples(b), computer with loaded software(c), iPhone app 'Seconds'(d), Zimmer ${ }^{\circledR}$ Surgical Motor System(e), water bath(f), saline bag(g), drill assembly(h), forceometer(i). 
This software allowed the capability of real-time measurements that were transferable to a Microsoft Excel spreadsheet. Furthermore, data acquisition was set to record temperatures at 1-second intervals until manually stopped. Therefore, initial baseline temperatures, maximum temperatures for $\mathrm{T}_{1}$ and $\mathrm{T}_{2}$, and all times and temperatures between start and stop at 1 -second were recorded with the software. Actual beginning and finish drilling times and range of force applied by operator were recorded manually.

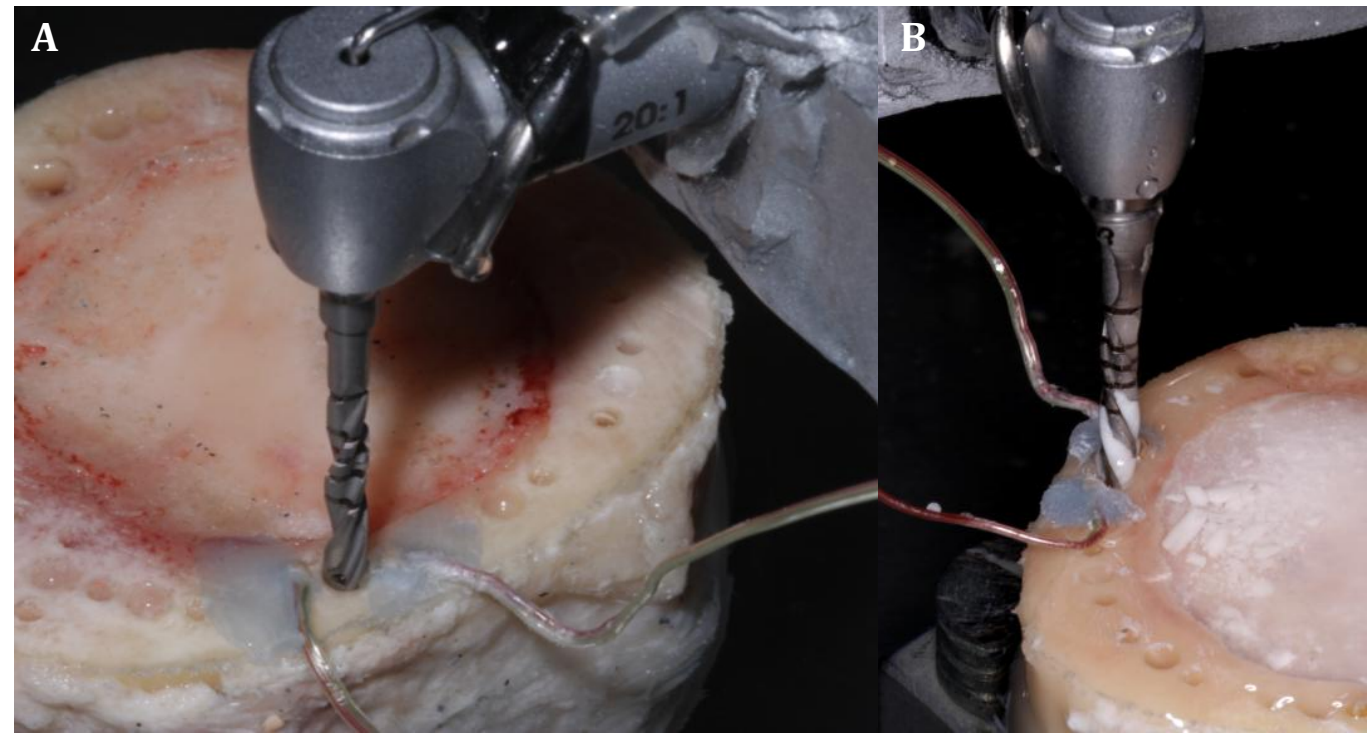

Fig. 11

Conventional drilling

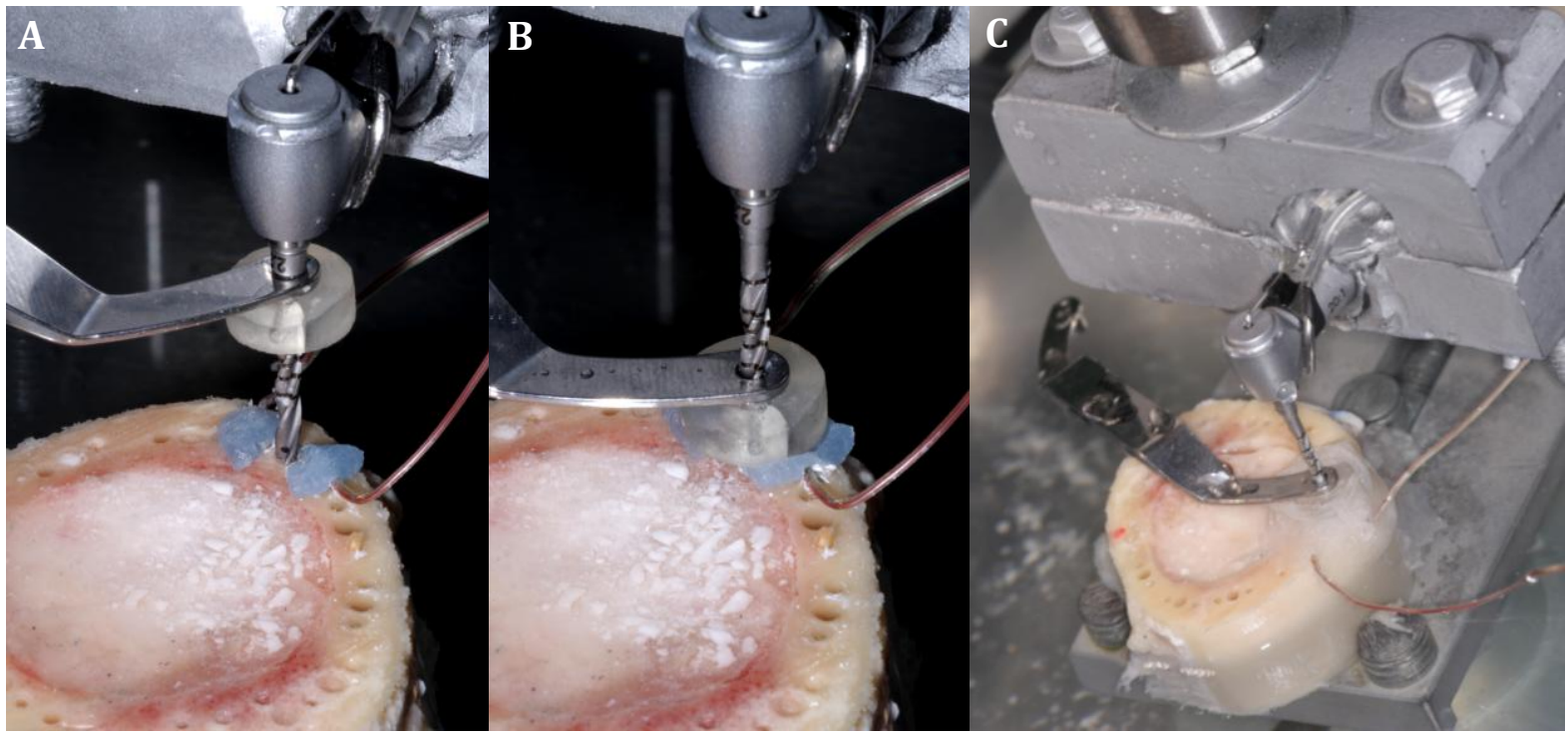

Fig. 12 Guided drilling: 2.3-mm twist drill inserted into the [tube adapter/metal sleeve] guide assembly. The drill is placed into the pre-drilled bony divot. $T_{1}$ and $T_{2}$ are in place and sealed with blue wax (A). Guide assembly is secured against bony specimen (B). Completed surgical guide with acrylic resin placed around guide assembly (C). 
All recorded values were stored in a personal computer and analyzed using the $\mathrm{JMP}^{\circledR}$ statistical discovery software program (JMP 10 for Windows; SAS ${ }^{\circledR}$ Institute Inc, Cary, NC). Statistical matched paired analyses were conducted using Wilcoxon signedrank tests, which is a non-parametric analogue to the paired t-test, which does not assume normally distributed data. This test is used to test for significant differences between two conditions of an independent variable in an experiment where the same (or matched) variables are responding in both conditions of the study. A significance level of 0.05 was employed in data analysis of this study. 


\section{Chapter IV}

\section{Results}

Measurements from the osteotomy preparations to each thermocouple $\left(\mathrm{T}_{1}\right.$ and $\left.\mathrm{T}_{2}\right)$ were obtained after each drilling. There was no statistically significant difference between the measured distances at $\mathrm{T}_{1}$ and $\mathrm{T}_{2}(P=0.17)$. The average amount of time to complete osteotomy preparations with and without a surgical guide was 24.78 seconds and 25.14 seconds, respectively. Using the median total drilling times for each, there was no statistically significant difference $(P=1.00)$ between using a guide versus no guide.

Temperature rise was significantly higher when the guide was used. Mean maximum temperatures obtained with the guide at $5 \mathrm{~mm}$ and $10 \mathrm{~mm}$ depths were $53.63^{\circ} \mathrm{C}$ and $53.24^{\circ} \mathrm{C}$, respectively, whereas

\section{Fig. 14 Maximum Temperatures Reached}

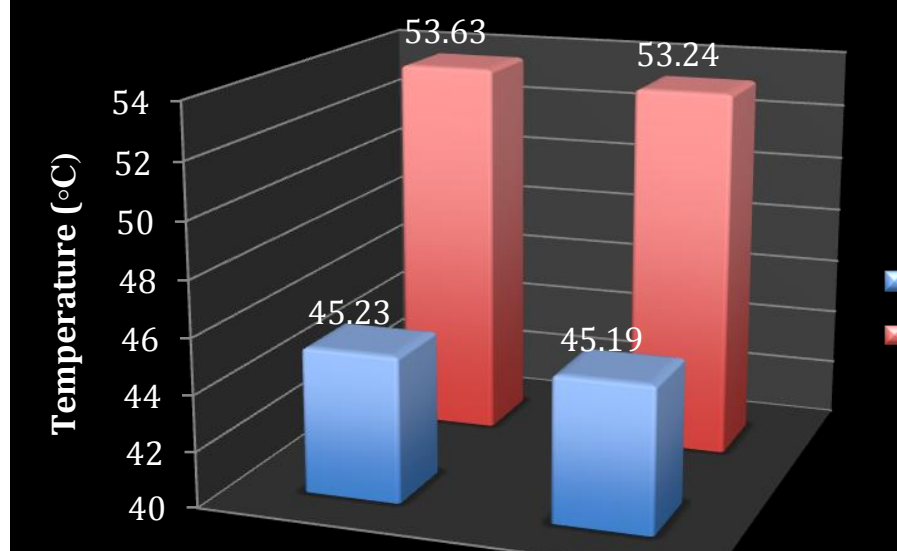

5 Depth (mm)
No Guide

@ Guide

Fig. 13

the mean maximum temperatures in conventional osteotomy preparations, or without the guide, at $5 \mathrm{~mm}$ and $10 \mathrm{~mm}$ depths were $45.23^{\circ} \mathrm{C}$ and $45.19^{\circ} \mathrm{C}$. Based on the Wilcoxon Signed Rank Test, a highly statistically significant difference was found at both the $5 \mathrm{~mm}$ depths $(P<0.0001)$ and at the $10 \mathrm{~mm}$ depths $(P<0.0001)$ between the guided and conventional drilling techniques and their associated maximum temperatures (Fig.14). 
Figure 15 shows the mean duration of time that temperatures were elevated to and beyond $47^{\circ} \mathrm{C}$. The average amount of time over the threshold level at $\mathrm{T}_{1}(5 \mathrm{~mm}$ depth $)$ was 17.80 seconds with the use of a guide and only 2.92 seconds without a guide. Likewise, the average amount of time over $47^{\circ} \mathrm{C}$ at $\mathrm{T}_{2}(10 \mathrm{~mm}$ depth) was 8.94 seconds and 2.92 seconds, with and without a guide, respectively. A statistically significant difference was found between the use of a guide and no guide and the duration of thermal rise at both $5 \mathrm{~mm}(P<0.0001)$ and $10 \mathrm{~mm}(P=0.0008)$ depths.

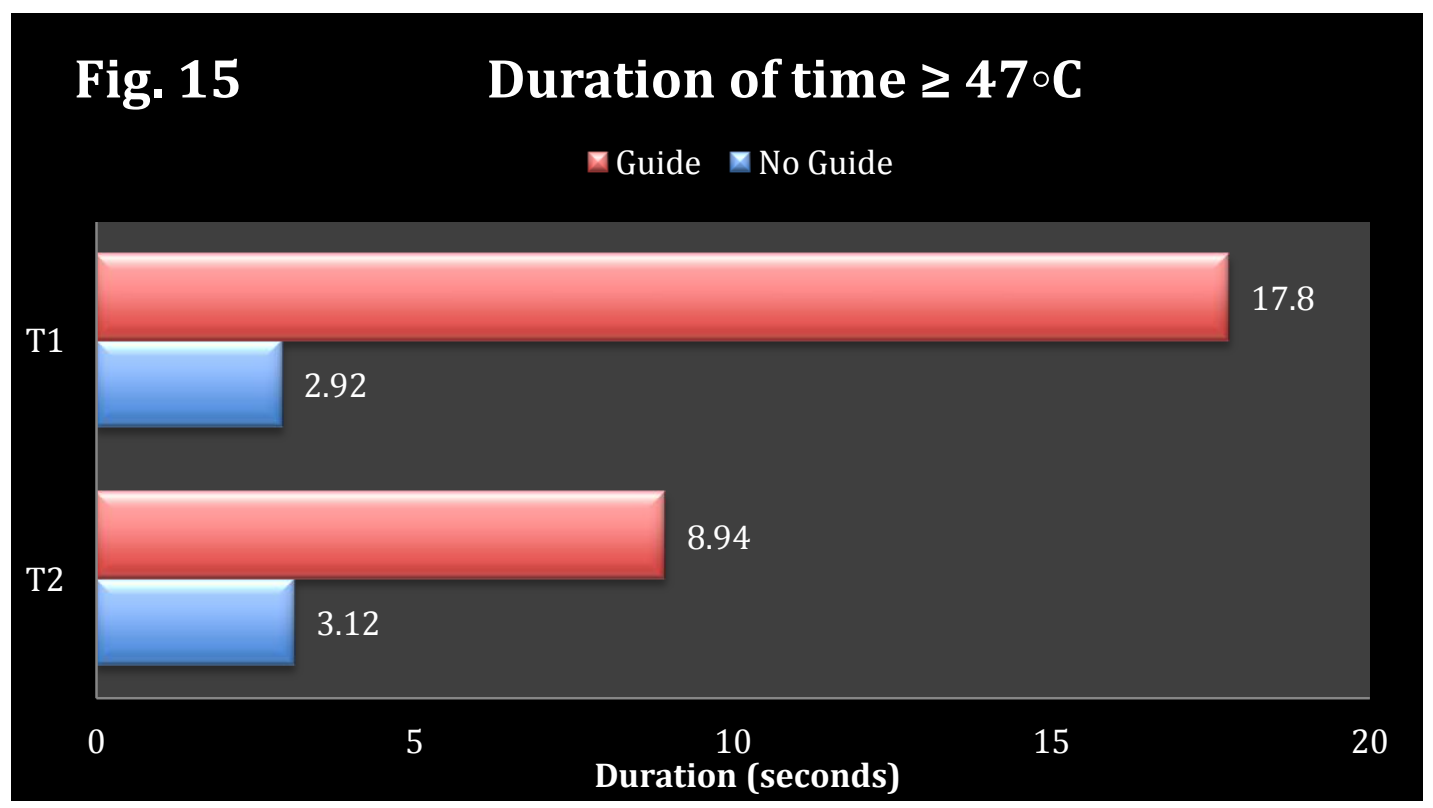




\section{Chapter V}

\section{Discussion}

The biologic bone is comprised of inorganic and organic components and the mechanical and thermological interaction among these components makes the testing and preparation of the bony specimen difficult to experiment upon. ${ }^{9}$ Similarly, the testing conditions, variability among heat assessment instruments, co-dependency of variables, evaluation of multiple parameters, and the lack of unity in the literature regarding various parameters makes the assessment of thermal injury to osseous tissue a complex topic to study. Additionally, the existence of multiple factors that co-exist and lead to the generation of heat during implant drilling further complicates testing conditions.

Tehemar classifies factors affecting heat generation during implant drilling to operator, manufacturer, site, or patient dependent. Parameters that have been found to lead to thermal injury include motor speed, drill sharpness, drill depth, force, cortical thickness of specimen, the drill diameter, modes of drilling (i.e. intermittent or continuous, graduated or one step), drill design (i.e. flute geometry), and irrigation. (Tehemar)

One parameter that has not been extensively investigated is the analysis of heat generation with and without the use of surgical guides. The effect of these surgical guides on heat generation was analyzed in this study. To decrease the error associated with multiple factors, all experimental conditions were kept constant except either using or not using a surgical guide when drilling.

An extensive literature review was conducted because so many variables were different among the studies, often varying among methodology and testing conditions. 
For the present study, 2,000 rpm was chosen for motor speed based on the osseointegration technique that calls for low speeds of 1,500 to 2,000 rpm. (Eriksson and Adell) Since various modes of irrigation can affect the outcomes of heat generation, the use of one implant system in which uses an internally and externally irrigation system (Zimmer®, Carlsbad, USA) was used to make the irrigation factor constant. Similarly, drill design and geometry, drill sharpness, and drill diameter was remained constant by utilizing only the 2.3-mm twist drill (Zimmer® Carlsbad, USA) and limiting each drill to twenty uses. Keeping the use of our drills to twenty is consistent with the Medical Data International report on the U.S. Implant market that recommends the replacement of dental implant drills after the preparation of twenty-five osteotomy cavities. (Chacon, Harris)

Bovine femoral bone was chosen in the conduction of this experiment due to ease of availability, an abundance of cortical bone, and similar thermal conductivity to human bone. Moreover, similar bone density and texture is found in the atrophic mandible of edentulous patients (i.e. in the preparation of mandibular implant overdentures). This is particularly significant because of the lack of vascularity and higher density in cortical bone, which consequently leads to higher drilling temperatures. The importance of cortical bone and its relevance to actual clinical situations is due to higher failure rates associated with type D1 (dense cortical) bone and its applicability to mandibular implant overdentures. (Brisman)

For standardization purposes, $10 \mathrm{~mm}$ drill depth was chosen as the osteotomy depths for this experiment which subsequently coincides with recommendations made by Brånemark - that $10 \mathrm{~mm}$ length is applicable for use in almost every edentulous jaw. 
(Brånemark) Furthermore, temperatures were recorded at this $10 \mathrm{~mm}$ depth, as well as a $5 \mathrm{~mm}$ depth, to quantify temperature elevations at crestal and deeper levels in the osteotomy site.

Intermittent fashion of drilling was chosen due to the lower temperatures generated with this technique in experiments of other studies. The osteotomy site was not widened to diameters larger than $2.3 \mathrm{~mm}$ since we believe that temperature elevations, even at the first pilot drill, are of clinical relevance. Studies have demonstrated that by widening the osteotomy site with a subsequently larger sized drill, similar temperatures may be maintained as the one preceding it. (Matthews and Hirsch)

Finally, due to energy losses and lack of consistency in the amount of force generated by using the drill press, a range of force between 2 to $8 \mathrm{~kg}$ was found to be consistent within the limits of this study. These forces were actually suggested by Matthews and Hirsch who recommended forces up to $12 \mathrm{~kg}$ to be applied to assure steady progression of sharp drills within cortical bone.

With the use of surgical guides, average temperature elevations up to $53.63^{\circ} \mathrm{C}$ were found at $5 \mathrm{~mm}$ depths and $53.24^{\circ} \mathrm{C}$ at $10 \mathrm{~mm}$ depths compared to $45.23^{\circ} \mathrm{C}$ and $45.19^{\circ} \mathrm{C}$ at 5 and $10 \mathrm{~mm}$ depths when drilling without a guide. We believe this to be caused by frictional heat from the intimate contact of the drill to metal sleeve guide assembly, clogging of drill flutes, accumulation of debris, and the lack of access of irrigant into the osteotomy site. Although it was necessary to clean the drills after each use, more time was required removing collection of bone debris from the flutes as well as the irrigation ports following the use of a surgical guide. 
When using a guide, similar maximum temperatures were found at $5 \mathrm{~mm}$ and $10 \mathrm{~mm}$. Likewise, when a guide was not used, the temperatures were similar at 5 $\mathrm{mm}$ and $10 \mathrm{~mm}$. This is contrary to the findings of Cordioli and Majzoub who found higher temperatures at $8 \mathrm{~mm}$ versus $4 \mathrm{~mm}$ depths. We find the similar temperatures at 5 and $10 \mathrm{~mm}$ to be due to the intermittent drilling and availability of irrigation making the temperatures at all levels equal within each testing condition.

Temperatures above the threshold level of $47^{\circ} \mathrm{C}$ were found at both 5 and 10 $\mathrm{mm}$ when using a guide; whereas maximum temperatures only reach up to $45^{\circ} \mathrm{C}$ without the use of a guide. Additionally, longer durations of temperature elevations above $47^{\circ} \mathrm{C}$, both at $5 \mathrm{~mm}$ and $10 \mathrm{~mm}$ depths, were found with the use of a surgical guide. However, longer average durations of thermal rise, up to 17.8 seconds were noticed at the $5 \mathrm{~mm}$ measurement compared to the $10 \mathrm{~mm}$ depth where durations up to 8.94 seconds were recorded. Once again, this longer duration of temperature elevation may be due to the clogging of debris and lack of irrigation delivery into the osteotomy site when using a surgical guide. Although the durations above $47^{\circ} \mathrm{C}$ were not above 1 minute, these durations may still be of clinical significance.

During guided preparations, several consistent findings were noted inefficiency of continuous internal irrigation at the tip of the drill, irrigation pooling over the guide instead of entering the osteotomy site, as well as significant bone debris collection found under the guide when it was removed from the specimen. For these reasons, the longer period at the $5 \mathrm{~mm}$ depths may be attributed to the inability of the bone debris to escape the guide and inability of irrigation to properly 
cool the site. Nevertheless, similar and shorter duration of temperature rise above $47^{\circ} \mathrm{C}$ at $5 \mathrm{~mm}$ and $10 \mathrm{~mm}$ with no guide shows the influence of the cooling effects of irrigation when it is not hindered.

As previously mentioned regarding instruments of heat assessment, the consistent measurements of thermocouples at $0.5 \mathrm{~mm}$ from the osteotomy site is of experimental value. The results of this study showed no statistically significant differences among the distances of the thermocouples placed at $\mathrm{T} 1$ and $\mathrm{T} 2$ adjacent to the osteotomy sites. We find the similarity among distances of thermocouples of experimental value since real-time measurements were recorded at consistent measurements from the osteotomy site.

Although we anticipated shorter duration times with the use of surgical guides, the results of this study show the total drilling time for the completion of 10 mm osteotomy sites with and without the use of surgical guide to be similar. Furthermore, since the duration of drilling time was the same, this is not a factor in heat generation between the two methods. Dissimilarly, in clinical settings, we have found the total drilling times of guided implant placement to be shorter in duration due to pre-planned and pre-designated implant sites. Therefore, caution needs to be taken when using surgical guides in regards to total drilling time ensuring bone removal is performed intermittently with limited amount of trauma induced into the osteotomy site.

Surgical guides have made challenging implant placement simple and predictable for both the treating clinician and the patient. Enhancement of technological advancements regarding the placement and restoration of implants 
are continuously being explored and improved; however, within the confines of this study, we found higher temperatures associated with the use of surgical guides. Care was taken to make temperature influencing parameters constant while parametrically analyzing the independent use of surgical guides and its effect of temperature elevation. Furthermore, we recommend future in vivo studies to correlate existence of temperature elevations in the clinical setting.

Our results are consistent with the findings of Misir et al who found elevated temperatures with the use of surgical guides in both internally and externally irrigated systems. Finally, we recommend that if a surgical guide is to be used, effective cooling must be achieved by intermittent drilling methods with copious irrigation and means of limiting the duration of temperature elevations above the threshold to achieve atraumatic osteotomy preparation.

Future considerations should involve the use of chilled irrigation to assess the influence of irrigation temperature on maximum temperature elevations during osteotomy preparation with and without the use of surgical guides. Subsequently, the effectiveness of internally irrigated systems should be compared with externally irrigated systems to draw a comparison for thermal changes during osteotomy preparations with and without the use of surgical guides. Finally, since our study was confined to the investigation of cortical bone, future studies should be conducted in a combination of cortical and cancellous bone, such as that of bovine rib bone. 


\section{Chapter VI}

\section{Conclusion}

Within the limits of this study, it can be concluded that:

- Surgical guides lead to higher temperature elevations as compared to drilling in cortical bone without a surgical guide.

- Longer durations of temperature elevation may be found with the subsequent use of surgical guides.

- Caution should be taken to avoid excessive temperature elevations when completing surgically guided osteotomy preparations. 


\section{Chapter VII}

\section{Appendix A}

\section{List of Figures}

Fig. 1 Fresh bovine leg bone prior to CT scan, sectioning and freezing. (p.54)

Fig. 2 Spiral CT Scan image of bovine bone specimen with indicated Housfield units shown. (p.55)

Fig. 3 Water bath assembly with two submergible aquarium heaters, thermometer, and bone specimen. (p.55)

Fig. 4 Complete drill press set up (A) drill press with labels for identification of parts (B). (p.55)

Fig. 6 Fabrication of paralleling jig. A Ney surveyor is used to set metal cylinder in cast base (p.56)

Fig. 7 (Left) Positioning of surgical handpiece using paralleling jig. (p.56)

Fig. 8 (Above) Surgical handpiece secured in acrylic block and mounted to drill press. $(p .56)$

Fig. 9 Positioning of the bovine specimen prior to drilling. The specimen was secured on a surveying table (A). A level was used on the bone specimen so drilling surface is parallel with horizontal plane $(B)$. (p.57)

\section{. Fig. 10}

Clear template guide is shown for drilling thermocouple holes and $T_{1}$ and $T_{2}$ holes marked accordingly for quick recognition. Pins are placed through the template into the thermocouples holes to secure the template in place to drill the divot (A).

After thermocouple holes and divots are completed, thermocouples are placed and secured with wax (B). (p.58)

Fig. 11 Conventional drilling (p.61)

Fig. 12 Guided drilling: 2.3-mm twist drill inserted into the [tube adapter/metal sleeve] guide assembly. The drill is placed into the pre-drilled bony divot. $T_{1}$ and $T_{2}$ are in place and sealed with blue wax (A). Guide assembly is secured against bony specimen (B). Completed surgical guide with acrylic resin placed around guide assembly $(C)$. (p.61)

Fig. 13 Complete experimental set up: 
data logger(a), K-type thermocouples(b), computer with loaded software(c), iPhone app 'Seconds'(d), Zimmer ${ }^{\circledR}$ Surgical Motor System(e), water bath(f), saline bag $(g)$, drill assembly $(h)$, forceometer $(i)$. (p.60)

Fig. 14 Graph: maximum temperatures reached (p.63)

Fig. 15 Graph: Duration of time greater than 47 degrees centigrade (p.64) 


\section{Chapter VIII}

\section{References}

1. The glossary of prosthodontic terms. J Prosthet Dent 1999; 81:39.

2. Abouzgia MB, James DF: Measurements of shaft speed while drilling through bone. Journal of oral and maxillofacial surgery : official journal of the American Association of Oral and Maxillofacial Surgeons 1995; 53:1308-1315.

3. Abouzgia M, James D: Temperature rise during drilling through bone. Int J Oral Maxillofac Implants 1997; 12:342-353.

4. Abouzgia MB, James DF: Measurements of shaft speed while drilling through bone. Journal of Oral and Maxillofacial Surgery 1996; 54:379379.

5. Abouzgia MB, Symington JM: Effect of drill speed on bone temperature. International Journal of Oral \& Maxillofacial Surgery 1996; 25:394-399.

6. Agren E, Arwill T: High-speed or conventional dental equipment for the removal of bone in oral surgery. III A histologic and microradiographic study on bone repair in the rabbit. Acta Odontol Scand 1968; 26:223--246.

7. Agren E, Arwill T: High-speed or conventional dental engines for the removal of bone in oral surgery. I. A study of the reactions following the removal of bilateral impacted lower molars. Acta Odontol Scand 1963; 21:585--625.

8. Albrektsson T: Measurements of shaft speed while drilling through bone. Journal of Oral and Maxillofacial Surgery 1995; 53:1315-1316.

9. Augustin G, Zigman T, Davila S, et al: Cortical bone drilling and thermal osteonecrosis. Clin Biomech (Bristol, Avon) 2012; 27:313-325. 
10. Benington IC, Biagioni PA, Crossey PJ, et al: Temperature changes in bovine mandibular bone during implant site preparation: an assessment using infra-red thermography. J Dent 1996; 24:263-267.

11. Benington IC, Biagioni PA, Briggs J, et al: Thermal changes observed at implant sites during internal and external irrigation. Clin Oral Implants Res 2002; 13:293-297.

12. Berman AT, Reid JS, Yanicko DR, et al: Thermally induced bone necrosis in rabbits. Relation to implant failure in humans. Clinical Orthopaedics and Related Research 1984; 186:284--292.

13. Boyne PJ: Histologic response of bone to sectioning by high-speed rotary instruments. J Dent Res 1966; 45:270--276.

14. Brånemark P-I.: Osseointegration and its experimental background. J Prosthet Dent 1983;50:399-410. J Prosthet Dent 1983; 50:399--410.

15. Brisman DL: The effect of speed, pressure, and time on bone temperature during the drilling of implant sites. Int J Oral Maxillofac Implants 1996; 11:35--37.

16. Calderwood RG, Hera SS, Davis JR, et al: A Comparison of the heating rate of bone after the production of defects by various rotary instruments. J Dent Res 1964; 43:207--216.

17. Chacon GE, Bower DL, Larsen PE, et al: Heat production by 3 implant drill systems after repeated drilling and sterilization. Journal of oral and maxillofacial surgery : official journal of the American Association of Oral and Maxillofacial Surgeons 2006; 64:265-269.

18. Cordioli G, Majzoub Z: Heat generation during implant site preparation: An in vitro study. Int J Oral Maxillofac Implants 1997; 12:186-193.

19. Cotisch ER, Youngblood PJ, Walden JM: A study of the effects of highspeed rotatory instruments on bone repair in dogs. J Oral Surg 1964; 17:563--571. 
20. Davidson SRH, James DF: Measurement of thermal conductivity of bovine cortical bone. $<$ br / > . Medical Engineering \& Physics 2000; 22:741--747.

21. D'haese J, Van De Velde T, Komiyama A, et al: Accuracy and Complications Using Computer-Designed Stereolithographic Surgical Guides for Oral Rehabilitation by Means of Dental Implants: A Review of the Literature. Clin Implant Dent Relat Res 2012; 14:321-335.

22. Ercoli C, Funkenbusch $\mathrm{P}$, Lee $\mathrm{H}$, et al: The influence of drill wear on cutting efficiency and heat production during osteotomy preparation for dental implants: A study of drill durability. Int J Oral Maxillofac Implants 2004; 19:335-349.

23. Eriksson A, Albrektsson T, Grane B, et al: Thermal Injury to bone. A vital microscopic description of heat effects. Int J Oral Surg 1982; 1:115$-121$.

24. Eriksson RA, Adell R: Temperatures during drilling for the placement of implants using the osseointegration technique. J Oral Maxillofac Surg 1986; 44:4--7.

25. Eriksson RA, Albrektsson T: The Effect of Heat on Bone Regeneration: An experimental study in the Rabbit using Bone Growth Chamber. J Oral Maxillofac Surg 1984; 48:705--711.

26. Eriksson RA, Albrektsson T: Temperature threshold levels for heatinduced bone tissue injury: A vital-microscopic study in the rabbit. J Prosthet Dent 1983; 50:101--107.

27. Fister J, Gross BD: A histologic evaluation of bone response to bur cutting with and without water coolant.. Oral Surg Oral Med Oral Pathol 1980; 49:105--111.

28. Haider R, Watzek G, Plenk HJ: Effects of drill cooling and bone structure on IMZ implant fixation. Int J Oral Maxillofac Implants 1993; 8:83--91. 
29. Harris B, Kohles S: Effects of mechanical and thermal fatigue on dental drill performance. Int J Oral Maxillofac Implants 2001; 16:819826.

30. HOBKIRK J, RUSINIAK K: INVESTIGATION OF VARIABLE FACTORS IN DRILLING BONE. JOURNAL OF ORAL SURGERY 1977; 35:968-973.

31. Jabero M, Sarment DP: Advanced surgical guidance technology: a review. Implant Dent 2006; 15:135-142.

32. Jochum RM, Reichart PA: Influence of multiple use of Timedurtitanium cannon drills: thermal response and scanning electron microscopic findings. Clin Oral Implants Res 2000; 11:139-139.

33. Kalidindi V: Optimization of drill design and coolant systems durin dental implant surgery, PhD thesis, . 2004.

34. Laurito D, Lamazza L, Garreffa G, et al: An alternative method to record rising temperatures during dental implant site preparation: a preliminary study using bovine bone. Ann Ist Super Sanità 2010; 46:405--410.

35. Lavelle C, Wedgwood D: Effectof internal irrigation on frictional heat generated from bone drilling. J Oral Surg 1980; 38:499--503.

36. MATTHEWS LS, HIRSCH C: Temperatures Measured in Human Cortical Bone when Drilling. Journal of Bone and Joint Surgery 1972; $54: 297$.

37. Misir AF, Sumer M, Yenisey M, et al: Effect of surgical drill guide on heat generated from implant drilling. Journal of oral and maxillofacial surgery : official journal of the American Association of Oral and Maxillofacial Surgeons 2009; 67:2663-2668.

38. Pohto M, Scheinin A: Effects of local anesthetic solutions on the circulation of the pulp in rat incisor. Bibl Anat 1960; 1:46.

39. Rafel SS: Temperature changes during high-speed drilling of bone. J Oral Surg 1962; 20:22--23. 
40. Sarment D, Sukovic P, Clinthorne N: Accuracy of implant placement with a stereolithographic surgical guide. Int J Oral Maxillofac Implants 2003; 18:571-577.

41. Sedlin E, Hirsch C: Factors Affecting the Determination of the Physical Properties of F emoral Cortical Bone. <br / >. Acta orthop. Scandinav 1966; 37:29--48.

42. Sharawy M, Misch CE, Weller N, et al: Heat generation during implant drilling: the significance of motor speed. . J Oral Maxillofac Surg 2002; 60:1160--1169.

43. Sutter F, Krekeler G, Schwammberger AE, et al: Atraumatic surgical technique and implant bed preparation. . Quintessence Int 1992; 23:811--816.

44. Tehemar S: Factors affecting heat generation during implant site preparation: A review of biologic observations and future considerations. Int J Oral Maxillofac Implants 1999; 14:127-136.

45. Thompson HC: Effect of drilling into bone. J Oral Surg 1958; 16:22-30.

46. W. Bonfield, C. H. Li: Deformation and Fracture of Bone. J Appl Phys 1966; 18:869-875.

47. WACHTER R, STOLL P: INCREASE OF TEMPERATURE DURING OSTEOTOMY - INVITRO AND INVIVO INVESTIGATIONS. Int J Oral Maxillofac Surg 1991; 20:245-249.

48. Weinlaender M: Bone Growth Around Dental Implants. Dent Clin North Am 1991; 35:585--601.

49. Weiss CM: Tissue integration of dental endosseous implants: description and comparative analysis of the fibro-osseous integration and osseous integration systems. . J Oral Implantol 1986; 12:169--214.

50. Yacker M, Klein M: The effect of irrigation on osteotomy depth and bur diameter. . Int J Oral Maxillofac Implants 1996; 11:634--638. 